\title{
MODELAGEM, CONTROLE E OTIMIZAÇÃO DO PROCESSO DOS FORNOS DE REAQUECIMENTO DE PLACAS
}

\author{
Bruno Otávio Soares Teixeira* \\ brunooteufmg.br
}

\author{
Fábio Gonçalves Jota*
}

fgjota@ufmg.br

\author{
Marcos Henrique Teixeira ${ }^{\dagger}$ \\ mhteixeira@usiminas.com.br \\ *Programa de Pós-Graduação em Engenharia Elétrica, Escola de Engenharia, Universidade Federal de Minas Gerais \\ Av. Antônio Carlos, 6627, 31270-901 - Belo Horizonte - MG - Brasil \\ ${ }^{\dagger}$ Gerência de Projetos, Instrumentação e Automação, Usiminas \\ Av. Pedro Linhares Gomes, 5431, 35160-900 - Ipatinga - MG - Brasil
}

\begin{abstract}
Reheating furnaces are commonly found in the steel industry for thermal treatment of slabs from continuous casting process. These slabs are uniformly reheated, following a suitable temperature profile so as to they can be sent to the milling stage with the necessary mecanical and metallurgical properties. Besides, it is desirable to have a satisfactory dynamic control of the temperature in order to reduce the fuel consumption, since the reheating process is the most expensive part of the whole hot strip mill plant.
\end{abstract}

In this paper it is presented the improvement developed in dynamic control in reheating furnace of hot strip mill plants of Usiminas. To achieve that, a methodology consisting of the application of a systematic experimental modeling, PI and PID controllers design, simulation, investigation of advanced control strategies (feedforward and switched controls and Smith predictor) and performance assessment has been used on main loops of process. Relative gain array metrics have been used to assess the input-output variable pairing and the coupling among the zones.

According to several tests performed in closed-loop (in the

\footnotetext{
Artigo submetido em $20 / 06 / 2006$

1a. Revisão em 08/01/2007

Aceito sob recomendação do Editor Associado

Prof. José Roberto Castilho Piqueira
}

real plant), the assessed results confirm the improvement achieved with the tuned control loops (by simulation). A reduction of $3.7 \%$ in the oil consumption has been observed, thanks to the improvement in the control loops and in the process efficiency. It means a monthly average saving of 182 thousand liters of oil.

KEYWORDS: Reheating furnace, mathematical modeling, advanced control, performance improvement.

\section{RESUMO}

Fornos de reaquecimento são comumente utilizados na indústria siderúrgica para aquecimento das placas de aço produzidas pelo processo de lingotamento. Essas placas devem ser reaquecidas, uniformemente, seguindo um perfil apropriado, de forma que elas tenham as propriedades mecânicas e metalúrgicas requeridas para sua laminação. Além disso, é desejável um controle dinâmico de temperatura nos fornos de reaquecimento satisfatório para que se reduza o consumo de combustível, já que tal consumo é responsável pela parcela mais onerosa dos custos de operação do processo de laminação a quente.

Este trabalho apresenta melhorias desenvolvidas no controle dinâmico dos Fornos de Reaquecimento de Placas da Linha de Tiras a Quente da Usiminas. Para isso, foi utilizada uma 
metodologia que consistiu na modelagem experimental, projeto, re-sintonia de controladores PI e PID, e estudo de estratégias de controle avançado (controles antecipatório e chaveado e preditor de Smith) para as principais malhas de vazão e temperatura que compõem o processo. A Matriz de Ganhos Relativos (MGR) foi utilizada para avaliar o melhor emparelhamento das variáveis de controle e o acoplamento das zonas.

Com o desenvolvimento deste trabalho, de acordo com os resultados de diversos testes em malha fechada, observaramse uma melhoria de desempenho nas malhas e um ganho de eficiência nos controles, responsáveis por uma redução mensal de 3,7\% no consumo do combustível, o que representa uma economia mensal média aproximada de 182 mil litros de óleo.

PALAVRAS-CHAVE: Forno de reaquecimento, modelagem matemática, controle avançado, melhoria de desempenho.

\section{INTRODUÇÃO}

Os fornos contínuos de reaquecimento de placas ou tarugos desempenham um papel importante na área de laminação de tiras a quente e de chapas grossas e nas usinas de produtos não planos. São neles que os produtos intermediários, como placas ou tarugos, são reaquecidos até se tornarem suficientemente plásticos para o processamento subseqüiente.

Além da sintonia dos parâmetros dos controladores PID, que constitui uma etapa obrigatória para a implementação de estratégias de controle avançado, é feita, neste trabalho, uma investigação de outras topologias de controle, considerando as características dinâmicas do processo em estudo.

Desde a década de setenta, os problemas de modelagem e controle de fornos de reaquecimento têm recebido considerável atenção (Yang e Lu, 1988). Podem ser levantadas duas principais razões para o interesse no estudo deste tipo de fornos. Primeiramente, estima-se que cerca de $15 \%$ do consumo global de energia nas indústrias siderúrgicas integradas ocorra em fornos de reaquecimento. O problema de controle de temperatura das placas não é trivial (Yang e Lu, 1986; Wang et al, 1999a) devido à complexidade do processo, à irregularidade da carga do forno (proporcionada pelas variações nas dimensões das placas), ao intervalo de tempo para desenfornamento das placas e às condições operacionais dos laminadores.

No estudo do controle de temperatura em fornos de reaquecimento, duas abordagens devem ser consideradas. A primeira delas foca no controle de temperatura das placas propriamente dito. A segunda foca no controle de temperatura da atmosfera do forno. Na primeira abordagem, na literatura técnico-científica, encontram-se vários trabalhos que tratam da modelagem das temperaturas das placas e da geração das curvas desejadas de aquecimento de cada uma delas, a partir das quais calculam-se as referências de temperaturas para cada zona do forno (Yang e Lu, 1986; Yang e Lu, 1988; Yoshitani et al., 1994; Sugita et al., 1997; García et al., 1998; Pedersen e Wittenmark, 1998; Wick e Köster, 1999; Wang et al., 1999a; Wang et al., 1999b; Pedersen e Wittenmark, 2001; Van Ditzhuijzen et al., 2002). Na segunda abordagem, considerando que o aquecimento das placas seja feito pela absorção da energia fornecida pela atmosfera do forno, surgem os problemas de controle de temperatura e das vazões de ar e de combustível queimado em cada zona. Essa abordagem representa o foco de estudo do presente trabalho.

O projeto de controladores e a implementação de técnicas de controle avançado pressupõem a existência de modelos matemáticos capazes de representar as características dinâmicas dominantes do processo. Assim sendo, modelos para as malhas do forno de reaquecimento devem ser previamente obtidos. É comum encontrar na literatura modelos matemáticos que descrevam o comportamento termodinâmico de aquecimento das placas em função da temperatura da atmosfera do forno de reaquecimento (Yang e Lu, 1986; Yang e Lu, 1988; Jiong, 1989; García et al., 1998; Pedersen e Wittenmark, 1998; Ko et al., 2000; Zhang et al., 2002; Van Ditzhuijzen et al., 2002). No entanto, modelos baseados na dinâmica da temperatura do forno (dados em função das vazões de combustível e de ar), parecem ser menos freqüentes.

Ko e colaboradores (2000) apresentam modelos, na forma de equações diferenciais não-lineares, para as temperaturas nas zonas de pré-aquecimento, aquecimento e encharque de um forno de reaquecimento, em função das pressões nas zonas, número de moles de combustíveis e de ar, e das capacidades térmicas das placas e das paredes do forno, dentre uma série de parâmetros termodinâmicos. Contudo, o uso de tal modelo para simulação do processo em estudo requer o levantamento de tais parâmetros. Modelos mais simples são apresentados em (García et al., 1998; Zhang et al., 2002; Van Ditzhuijzen et al., 2002). Todavia, esses ainda requerem o conhecimento de alguns parâmetros característicos do sistema, os quais são, geralmente, variáveis em função das condições de operação do processo.

Dessa maneira, quer pela complexidade dos modelos baseados na física do processo, os quais resultam em equações diferenciais não-lineares com parâmetros distribuídos, quer pela necessidade de estruturas lineares simplificadas para o projeto de controladores, técnicas de identificação de sistemas constituem uma opção para a modelagem dos fenômenos dinâmicos que ocorrem entre as vazões de combustíveis e de ar e as temperaturas nas zonas do forno, conforme é proposto em (Kusters e Van Ditzhuijzen et al., 1994; Rohál'- 
Ilkinv et al., 1994; Dunoyer et al., 1997; Wang et al., 1999b; Ko et al., 2000; Van Ditzhuijzen et al., 2002). Sob o paradigma da identificação caixa preta, estruturas de primeira ou de segunda ordem com atraso puro de tempo, para um dado ponto operacional, são, geralmente, escolhidas para representação de modelos na forma de funções de transferência (Wang et al., 1999b) ou, mais comumente, equações de diferenças, conforme é feito em (Kusters e Van Ditzhuijzen, 1994; Rohál'-Ilkinv et al., 1994; Ko et al., 2000; Van Ditzhuijzen et al., 2002).

Uma outra alternativa é sugerida por Dunoyer e colaboradores (1997), a qual propõe o uso de modelos bilineares para as malhas de temperatura de fornos de reaquecimento. Ele argumenta que, ao contrário dos modelos lineares, cujos parâmetros variam significantemente de um ponto de operação para outro, os parâmetros dos modelos bilineares são, praticamente, constantes para aplicações em fornos que lidam com elevadas temperaturas, como é o caso dos fornos de reaquecimento.

O acoplamento entre as zonas de um forno de reaquecimento é uma questão fundamental que influencia sua modelagem. Essa abordagem é tratada em maiores detalhes em (Kusters e Van Ditzhuijzen et al., 1994; Wang et al., 1999b; Ko et $a l .$, 2000). Esse acoplamento ocorre em função da conexão física existente entre tais zonas e do sistema de controle da pressão interna, o qual favorece um deslocamento do fluxo de calor da zona de encharque (saída do forno) para a de pré-aquecimento (entrada do forno). Dessa maneira, modelos multivariáveis são sugeridos pela literatura (Rohál'-Ilkinv et al., 1994; Wang et al., 1999b).

O projeto de controladores eficazes e a implementação de técnicas de controle avançado em fornos de reaquecimento é uma tarefa ainda mais desafiadora, considerando a complexidade do processo, suas características não-lineares, atrasos puros de tempo significativos, constantes de tempo elevadas, considerável acoplamento entre as zonas, variações na pressão interna do forno e vários outros fatores de incerteza (Wang et al., 1999a; Wang et al., 1999b; Zhang et al., 2002).

Além disso, a garantia da qualidade do aquecimento das placas de aço e a estratégia de controle utilizada nas malhas de temperatura em um forno de reaquecimento precisam garantir o consumo mínimo de energia. A estratégia avançada mais sugerida é a de controle adaptativo, sendo os controladores preditivos generalizados as estruturas mais comumente encontradas (Clarke et al., 1986; Rohál'-Ilkinv et al., 1994; Dunoyer et al., 1997; Ko et al., 2000; Zhang et al., 2002; Van Ditzhuijzen et al., 2002).

As principais motivações apresentadas em (Dunoyer et al., 1997; Zhang et al., 2002) para o emprego de técnicas de controle auto-sintonizável são as características não-lineares do processo, o forte acoplamento entre as malhas de controle de temperatura, o atraso puro de tempo significativo, as constantes de tempo elevadas e variáveis de acordo com o ponto de operação da planta.

Já Wang e colaboradores (1999b), considerando que os fornos de reaquecimento são sistemas multivariáveis com forte acoplamento e com grandes atrasos puros de tempo, propõem a implementação de desacopladores dinâmicos e preditores de Smith. Uma outra corrente defende a aplicação de técnicas de inteligência computacional como lógica nebulosa para o projeto de controladores difusos (Jiong, 1989). Como principal vantagem advinda da adoção de técnicas avançadas, é citada uma economia média no consumo de combustível de 9\% em (Rohál'-Ilkinv et al., 1994), 1\% em (Dunoyer et al., 1997) e 3\% em (Wang et al., 1999b). Todavia, tais estudos não explicitam se os controladores PID clássicos em comparação estavam razoavelmente bem sintonizados, caso contrário, a expressividade dos resultados mostrados pode ser questionável.

Assim, este documento está organizado da seguinte maneira: a Seção 2 apresenta uma descrição do processo em estudo, destacando os principais problemas no controle do processo. A Seção 3 trata da modelagem matemática do processo mostrando as técnicas e metodologia adotada. O projeto de controladores PI e PID para as malhas de vazão e de temperatura e a investigação das técnicas de controle antecipatório, chaveado e preditor de Smith para as malhas de temperatura são abordados na Seção 4. Em seguida, a Seção 5 trata dos resultados experimentais obtidos a partir da implementação dos controladores projetados e das técnicas de controle empregadas. Finalmente, apresentam-se as conclusões.

\section{DESCRIÇÃO DO PROCESSO}

Em linhas de tiras a quente (Figura 1), placas com espessura entre 150 e $250 \mathrm{~mm}$ são aquecidas em um forno de reaquecimento. Quando a temperatura de desenfornamento da placa está dentro das condições desejadas, essas são extraídas e transportadas para um ou mais laminadores desbastadores, onde a espessura é reduzida para 25 a $32 \mathrm{~mm}$. Então, a placa entra em um laminador acabador composto de 5 a 7 cadeiras equipado com AGC hidráulico, ${ }^{1}$ onde a espessura é reduzida para o valor desejado ( 1 a $18 \mathrm{~mm}$ ), sendo a placa transformada em uma tira. Depois do laminador acabador, a tira é resfriada na mesa de saída por meio de um sistema de resfriamento do tipo cortina d'água e tubo U com seções de resfriamento. Dependendo do tipo do aço, a temperatura deve estar entre $850^{\circ} \mathrm{C}$ a $920^{\circ} \mathrm{C}$ durante a última redução no laminador acabador. A partir dessa última temperatura e das

\footnotetext{
${ }^{1} \mathrm{O}$ acrônimo AGC (do inglês, Automatic Gauge Control) refere-se ao sistema de controle automático de ganho que defi ne a espessura da tira.
} 
perdas de calor ocorridas durante o processo de laminação, a temperatura de desenfornamento da placa é determinada.

O forno de reaquecimento de placas é o primeiro equipamento da linha, logo após o pátio de armazenamento de placas. Neste pátio, as placas, oriundas da máquina de lingotamento contínuo, aguardam o momento quando serão enfornadas a quente (caso em que a temperatura de enfornamento é superior a $200^{\circ} \mathrm{C}$ ) ou a frio (inferior a $200^{\circ} \mathrm{C}$ ).

A laminação de tiras a quente da Usiminas possui 3 fornos, 2 do tipo walking beam (Fornos 4 e 5) e um pusher (Forno 3). Escolheu-se o Forno 4 para o desenvolvimento deste trabalho por este apresentar o maior consumo de energia. A estrutura desse forno é mostrada na Figura 2. Nos fornos, as placas são transportadas da zona de carga até a zona de encharque sendo aquecidas até a temperatura adequada para os processos de laminação. O controle desta temperatura é muito importante dentro do processo de laminação, pois a obtenção das dimensões, forma e características metalúrgicas e mecânicas requeridas pelo cliente estão inteiramente relacionadas a este fator. A área de controle desse forno é dividida em 6 zonas, as quais são denominadas zonas pré-aquecimento superior e inferior (codificadas 411 e 421, respectivamente), aquecimento superior e inferior (431 e 441) e encharque superior e inferior (451 e 461). Em cada uma dessas zonas, existem queimadores (um total de 50 no Forno 4) que têm as vazões de combustível e de ar ajustadas de forma independente, através da abertura e fechamento de válvulas. As zonas de aquecimento e encharque utilizam uma mistura de gases do processo, proveniente da coqueria (COG), altos-fornos (BFG) e aciaria (LDG). Para a zona de pré-aquecimento, é mais comum queimar óleo atomizado com vapor de água, devido ao fato de que a disponibilidade de gases de processo não é suficiente para atender a demanda de produção. A zona de carga não é controlada e não tem queimadores de combustíveis. Os aspectos relacionados ao controle da temperatura no forno de reaquecimento são tratados neste artigo. Para fornos com mais zonas, a abordagem de controle é semelhante.

A zona de pré-aquecimento, onde ocorre com maior intensidade a troca de calor entre a atmosfera do forno e as placas, possui aproximadamente 13 metros de comprimento e comporta, em média, 12 placas. Os outros 20 metros são divididos entre o aquecimento, com 9 metros, o encharque, com 8 metros, e a zona de carga, com os 3 metros restantes. A função da zona de pré-aquecimento $(411$ e 421$)$ e do aquecimento (431 e 441) é aquecer as placas e, a da zona de encharque é homogeneizar a temperatura ao longo das mesmas. Pela própria construção física do forno, pode-se perceber que existe uma ligação entre as zonas do forno (Figura 2). Para obter o controle da temperatura da placa, as ações a serem tomadas são algumas vezes contraditórias. Por exemplo, quando se opera o forno acompanhando o ritmo do lamina- dor, objetivando ajustar a temperatura de desenfornamento, o consumo de combustível tende a ser elevado devido à variedade de dimensões e tipos de materiais enfornados. Por outro lado, quando se opera com o objetivo principal de redução de combustível, pode-se não obter a condição térmica adequada da placa. Assim, a operação em manual dos fornos, por mais experiente que seja o operador, não permite a otimização operacional. Devido ao grande número de variáveis envolvidas e às restrições inerentes ao processo, somente um sistema controlado por computador permite realizar tal otimização.

Normalmente, dois níveis de controle são empregados no controle de temperatura. Essa hierarquia de controle é mostrada na Figura 3. No nível 1, a temperatura da zona é controlada através de controladores (TIC), um para cada zona, que são interligados a controladores de vazão de combustíveis e de ar (FIC), sendo 2 por zona, numa configuração em cascata, via duplo limite cruzado. Termopares instalados próximos às paredes internas do forno medem as temperaturas das zonas, as quais são controladas pelo sistema de otimização dos fornos (FCC) composto pelo computador de processo de nível 2. O setpoint (SP) para essas zonas é definido pelo nível 2, onde a estratégia de temperatura ótima é definida e enviada online para os controladores de temperatura. A premissa dessa estratégia é que cada zona deve ser controlada por queimadores independentes. No entanto, como as zonas são interligadas, há uma interação dinâmica entre elas, afetando o desempenho do sistema de controle da temperatura do forno. Como o sistema de controle desconsidera o acoplamento entre as malhas de temperatura, neste artigo, é avaliado o grau de acoplamento (interação) entre as malhas de temperatura e o que pode ser feito em tal sistema de controle para minimizar este efeito. A construção física do forno, aliada ao seu sistema de controle da pressão interna (o qual é feito por meio da abertura da comporta de dumper antes do enfornamento de placas), promove um fluxo de calor da zona de encharque para a zona de preaquecimento. Neste artigo, é dada ênfase maior às malhas de temperatura e de vazão das zonas do forno (por serem estas as que têm maior influência em seu desempenho).

Conforme a recomendação de estratégia de controle para malhas de temperatura (Shinskey, 1988; Seborg et al., 1989), os fornos de reaquecimento da Usiminas utilizam controladores PID. Tais controladores PID discretos empregam algoritmos de velocidade que impedem a ocorrência de efeito windup e permitem a transferência manual/automático sem solavanco (Åström e Hägglund, 1995).

Apesar de o forno possuir seis zonas, oito controladores PID são empregados. Isso se deve ao fato da câmara de préaquecimento poder operar com óleo ou gás de processo como combustível. Dada a diferença entre o poder calorífico desses 


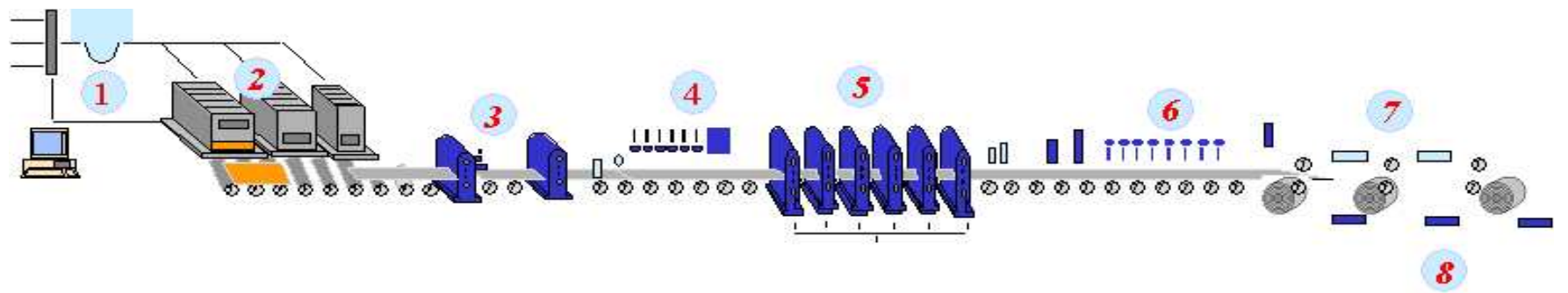

Figura 1: Diagrama da linha de tiras a quente da Usiminas: (1) pátio de placas; (2) fornos de reaquecimento; (3) laminadores desbastador e esboçador; (4) conservador de calor; (5) laminador acabador; (6) sistema de resfriamento; (7) bobinadeiras e (8) inspeção intermediária.

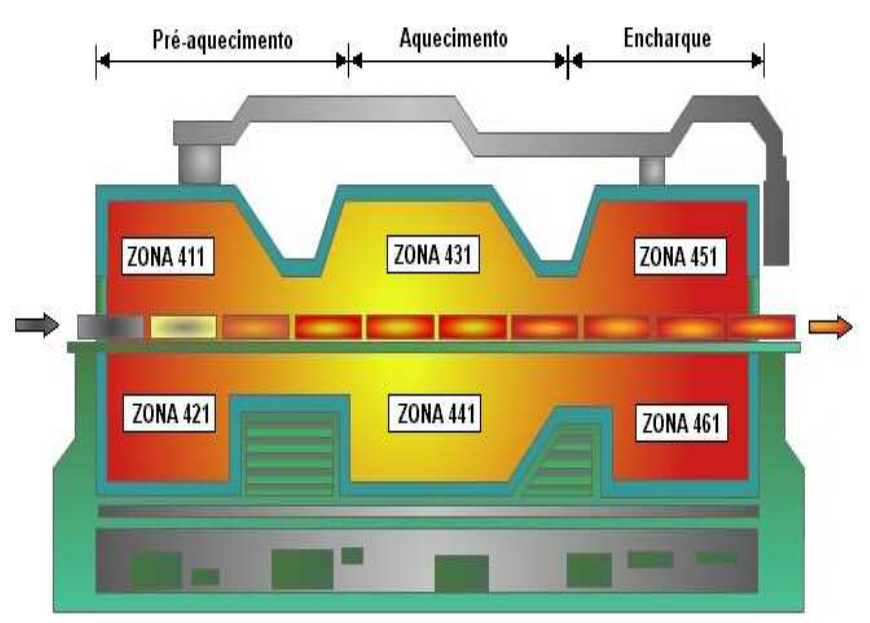

Figura 2: Esquema da estrutura do forno de reaquecimento.

combustíveis, no forno da Usiminas, são utilizados controladores distintos para uso do gás e do óleo. Com relação à rede de instrumentação das malhas de temperatura, estão instalados, em cada zona, dois termopares do tipo $\mathrm{S}$, com compensação de junta fria. Os sensores em questão são identificados pelos rótulos TI-4X1 e TI-4X2, em que X é o código da zona e varia de 1 a 6 . Os transmissores de temperatura TI-4X1 e TI-4X2 apresentam resolução de $0,2^{\circ} \mathrm{C}$ e estão calibrados na faixa entre 700 a $1400^{\circ} \mathrm{C}$. A média aritmética do sinal medido pelos dois termopares de cada zona é tomada como a temperatura média da mesma.

Para as malhas de temperatura, o valor de setpoint indica o valor desejado de temperatura para uma dada zona do forno, o qual é calculado pelo sistema de otimização (nível 2). O valor da variável de processo $(\mathrm{PV})$ corresponde à média aritmética dos valores indicados pelos dois termopares instalados em cada zona e, a variável manipulada (MV) tem seu valor fornecido pelo controlador PID da zona de temperatura correspondente.

Para as malhas de vazão do Forno 4, são usados controla-

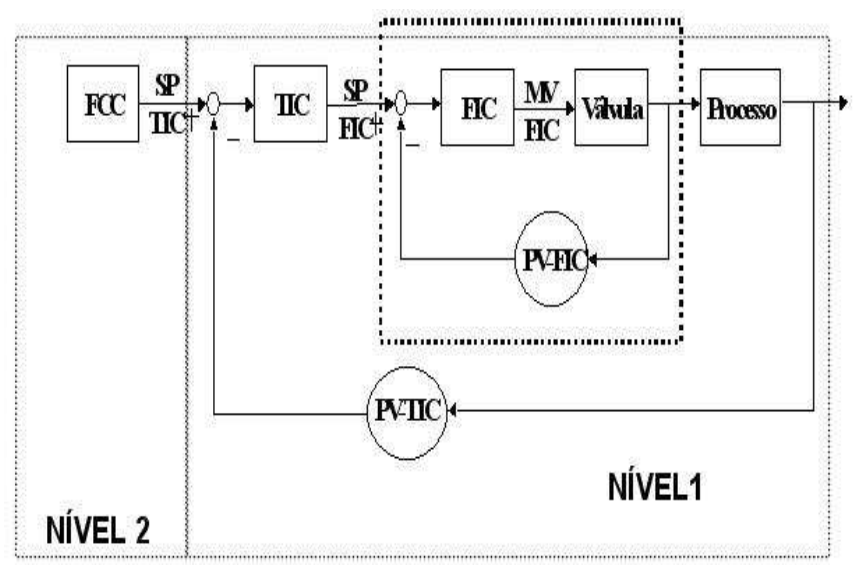

Figura 3: Hierarquia do sistema de controle distribuído (DCS) do forno de reaquecimento, no qual o setpoint para cada malha de temperatura é determinado por um sistema de otimização (FCC).

dores PI. De acordo com Shinskey (1988) e Seborg et al. (1989), a ação derivativa não é recomendável para as malhas de vazão porque essa variável já possui uma dinâmica consideravelmente rápida e seus medidores geralmente produzem sinais significativamente ruidosos. Na Tabela 1, são listados as dezesseis malhas de vazão do forno em estudo por zona, todas operando em malha fechada.

Todas as malhas de vazão dispõem de placas de orifício para medição da vazão. Os transmissores de pressão diferencial das malhas de gás possuem compensação de densidade, enquanto que os transmissores das malhas de ar apresentam compensação de temperatura. Os atuadores das malhas de vazão de gás e de ar são válvulas do tipo borboleta com posicionadores pneumáticos. Já as malhas de vazão de óleo e de vapor possuem válvulas do tipo globo com posicionadores a diafragma.

Em suma, objetiva-se, ao descrever os principais sistemas de controle e ao destacar algumas variáveis que influenciam 
Tabela 1: Lista por zona das malhas de vazão do forno de reaquecimento em estudo.

\begin{tabular}{|c|c|c|c|c|}
\hline Zona & $\begin{array}{c}\text { Vazão } \\
\text { de ar }\end{array}$ & $\begin{array}{c}\text { Vazão } \\
\text { de gás }\end{array}$ & $\begin{array}{c}\text { Vazão } \\
\text { de óleo }\end{array}$ & $\begin{array}{c}\text { Vazão } \\
\text { de } \\
\text { vapor }\end{array}$ \\
\hline $\begin{array}{c}\text { Pré- } \\
\text { aquecimento } \\
\text { Superior }\end{array}$ & AFIC411 & GFIC411 & OFIC411 & SFIC411 \\
\hline $\begin{array}{c}\text { Pré- } \\
\text { aquecimento } \\
\text { inferior }\end{array}$ & AFIC421 & GFIC421 & OFIC421 & SFIC421 \\
\hline $\begin{array}{c}\text { Aquecimento } \\
\text { superior }\end{array}$ & AFIC431 & GFIC431 & & \\
\hline $\begin{array}{c}\text { Aquecimento } \\
\text { inferior }\end{array}$ & AFIC441 & GFIC441 & & \\
\hline $\begin{array}{c}\text { Encharque } \\
\text { superior }\end{array}$ & AFIC451 & GFIC451 & & \\
\hline $\begin{array}{c}\text { Encharque } \\
\text { inferior }\end{array}$ & AFIC461 & GFIC461 & & \\
\hline
\end{tabular}

em seu desempenho, dar uma visão da construção física do forno, e sintetizar os problemas mais comumente existentes, tais como:

- a existência de um acoplamento entre as zonas de préaquecimento, aquecimento e encharque;

- a existência de uma relação entre as variáveis de processo que afetam diretamente a combustão;

- as perturbações causadas pelo tipo de carga em processamento no forno e devido ao acoplamento entre as zonas.

\section{MODELAGEM MATEMÁTICA}

Neste artigo, foi empregado o método da resposta complementar (Doebelin, 1990; Rodrigues et al., 1998) para obtenção dos parâmetros das funções de transferência $G_{P}(s)$ de primeira ordem com atraso puro de tempo das malhas de vazão bem como as de segunda ordem sobreamortecidas (ou mesmo de primeira ordem) com atraso puro de tempo das malhas de temperatura. Outros métodos de identificação poderiam ter sido utlizados (Ljung, 1987; Doebelin, 1980; Åstrom e Hägglund, 1995; Aguirre, 2004). Entretanto, para as malhas em questão, o método da resposta complementar mostrou-se suficiente para determinação dos parâmetros dos modelos da dinâmica dominante.

\subsection{Malhas de Vazão}

Objetivando-se caracterizar a resposta dinâmica das malhas de vazão de combustível e de ar de cada zona do forno, definiu-se um procedimento constituído de três etapas. A fim de ilustrá-lo, é utilizada a malha de vazão de óleo da zona de pré-aquecimento superior (OFIC411).

Primeiramente, testes ao degrau em malha aberta, em toda a faixa de operação, são realizados. A Figura 4 ilustra os resultados obtidos sendo a curva MV-OFIC411 a variável manipulada e a PV-OFIC411 a variável controlada. Na segunda etapa, calculam-se os valores de ganho em estado estacionário da referida malha em cada ponto de operação e, por regressão linear, conforme mostra a Figura 5, os ganhos médios de subida e de descida, que são, para este exemplo, 49,0 e 48,5, respectivamente. $\mathrm{O}$ terceiro passo constitui em caracterizar dinamicamente a malha pela obtenção da constante de tempo dominante $(\tau)$ e do atraso puro de tempo $(\theta)$. Para tal, escolhem-se dois testes de resposta ao degrau (um de subida e outro de descida), dentre todos mostrados na Figura 4, a partir dos quais os parâmetros supracitados são obtidos. Para o exemplo em questão, escolhem-se os degraus de subida de $35 \%$ a $45 \%$ e o de descida de $35 \%$ a $25 \%$. Esses intervalos são escolhidos em função da faixa de operação linear da válvula e de sua região de operação mais freqüente. Quando necessário, mais de dois modelos são obtidos. Em seguida, ajustes finos são feitos a fim de obter modelos que representem razoavelmente o comportamento de subida e o de descida de cada válvula para qualquer ponto de operação. A Figura 6 ilustra os resultados obtidos pela validação dos modelos médios obtidos para a OFIC411. Obtiveram-se $2 \mathrm{~s}$ como atraso puro de tempo e 4,0s e 4,5s, respectivamente, como constantes de tempo na subida e na descida.
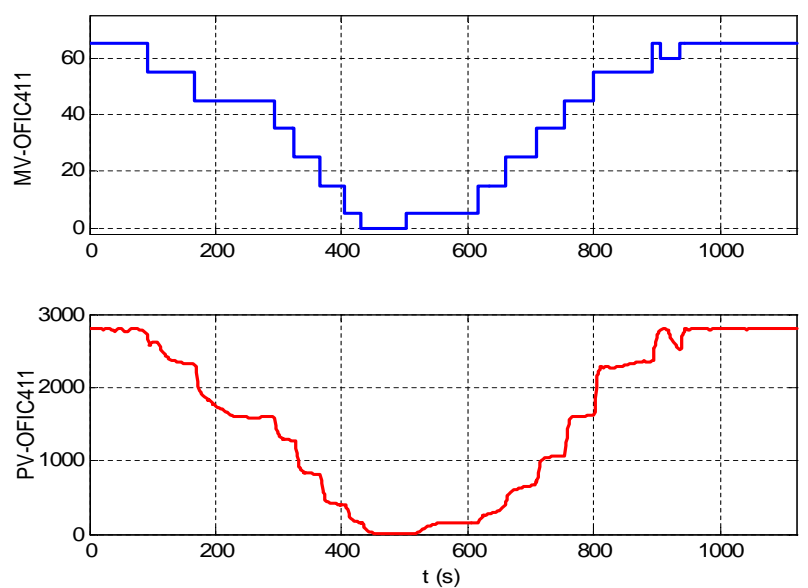

Figura 4: Dados de MV (percentual de abertura da válvula) e PV (vazão de óleo em L/h) dos testes ao degrau em malha aberta para a malha de vazão de óleo OFIC411. 


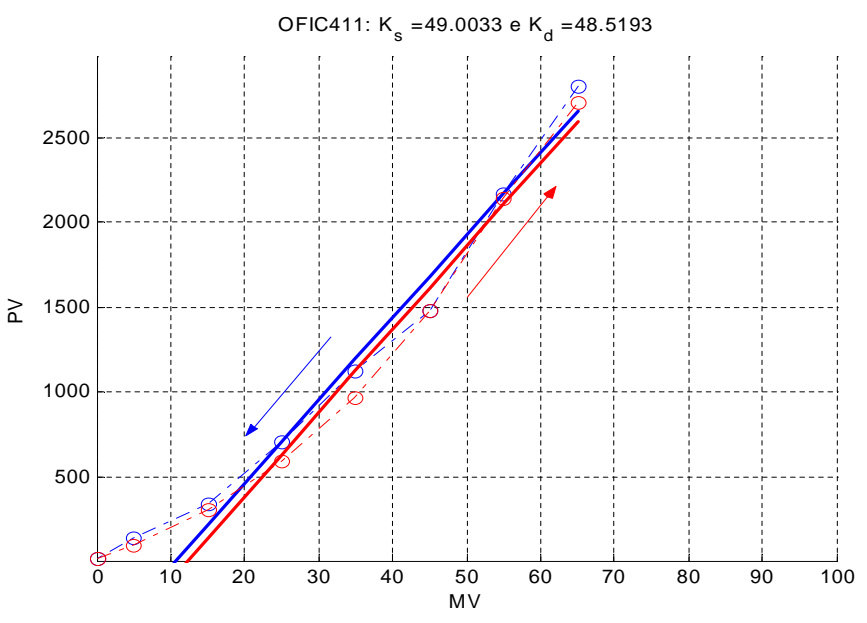

Figura 5: Curvas de descida e de subida do ganho estacionário da válvula OFIC411.
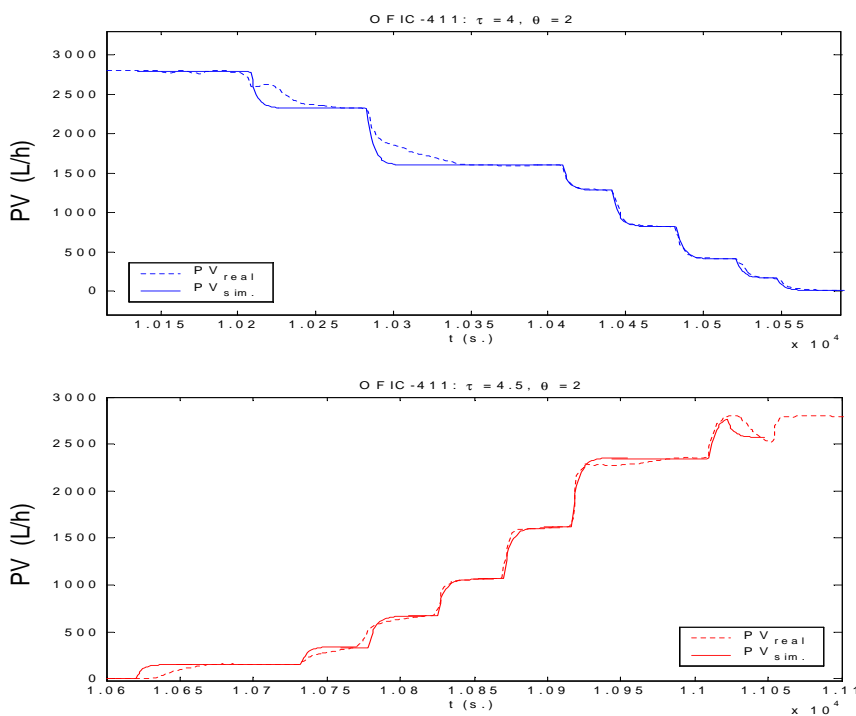

Figura 6: Simulação em malha aberta para a malha de vazão de óleo OFIC411. Na parte superior, compara-se a simulação com o teste de descida, na inferior, com o de subida.

A Tabela 2 resume os modelos médios de subida e de descida obtidos para cada uma das 14 malhas de vazão investigadas, bem como os valores máximos e mínimos de ganhos observados em toda faixa testada (a qual é explicitada nas segunda e terceira colunas). A modelagem das malhas de vazão foi realizada em dois momentos distintos. A primeira sintonia foi finalizada em 2003 (primeira linha de cada malha) e a segunda em 2004 (segunda linha de cada malha), após a reforma do forno.
Tabela 2: Parâmetros dos modelos dinâmicos das malhas de vazão de gás, óleo e ar. Os ganhos das válvulas são dados em (KNm3/h)/\% (gás e ar), ou (L/h)/\% (óleo).

\begin{tabular}{|c|c|c|c|c|c|c|c|}
\hline \multirow[t]{2}{*}{ Malha } & \multicolumn{4}{|c|}{ Ganho estático } & \multicolumn{2}{|c|}{$\begin{array}{l}\text { Constante } \\
\text { de tempo }\end{array}$} & \multirow[t]{2}{*}{$\theta$} \\
\hline & $\begin{array}{c}\text { Ganho } \\
\text { descida } \\
\text { (faixa } \\
\text { MV) }\end{array}$ & $\begin{array}{c}\text { Ganho } \\
\text { subida } \\
\text { (faixa } \\
\text { MV) }\end{array}$ & Mín & Máx & Des. & Sub. & \\
\hline \multirow[t]{2}{*}{$\begin{array}{c}\text { GFIC- } \\
411\end{array}$} & $\begin{array}{c}0,2188 \\
(27- \\
67 \%)\end{array}$ & $\begin{array}{c}0,2535 \\
(27- \\
67 \%)\end{array}$ & 0,10 & 0,47 & 3,75 & 2,0 & 2 \\
\hline & $\begin{array}{c}0,43 \\
(15- \\
35 \%)\end{array}$ & $\begin{array}{l}0,44 \\
(15- \\
35 \%)\end{array}$ & 0,33 & 0,54 & 4,69 & 4,69 & 2 \\
\hline \multirow[t]{2}{*}{$\begin{array}{c}\text { GFIC- } \\
421\end{array}$} & $\begin{array}{c}0,3145 \\
(10- \\
50 \%)\end{array}$ & $\begin{array}{c}0,3283 \\
(20- \\
60 \%)\end{array}$ & 0,26 & 0,36 & 2,5 & 2,0 & 2 \\
\hline & $\begin{array}{c}0,41 \\
(10- \\
40 \%)\end{array}$ & $\begin{array}{c}0,41 \\
(10-40 \\
\%)\end{array}$ & 0,26 & 0,44 & 6,28 & 6,10 & 2 \\
\hline \multirow[t]{2}{*}{$\begin{array}{c}\text { GFIC- } \\
431\end{array}$} & $\begin{array}{c}0,1835 \\
(15- \\
55 \%) \\
\end{array}$ & $\begin{array}{c}0,1736 \\
(15- \\
55 \%)\end{array}$ & 0,15 & 0,23 & 2,75 & 2,75 & 2 \\
\hline & $\begin{array}{c}0,18 \\
(17-52 \\
\%)\end{array}$ & $\begin{array}{c}0,18 \\
(17-52 \\
\%) \\
\end{array}$ & 0,15 & 0,22 & 5,75 & 5,67 & \\
\hline \multirow[t]{2}{*}{$\begin{array}{c}\text { GFIC- } \\
441 \\
\end{array}$} & $\begin{array}{c}0,2402 \\
(5-45 \%)\end{array}$ & $\begin{array}{c}0,2401 \\
(5-45 \%)\end{array}$ & 0,22 & 0,27 & 2,5 & 2,5 & 1 \\
\hline & $\begin{array}{c}0,26 \\
(10- \\
50 \%) \\
\end{array}$ & $\begin{array}{c}0,25 \\
(10- \\
50 \%) \\
\end{array}$ & 0,15 & 0,29 & 4,37 & 4,78 & 1 \\
\hline \multirow[t]{2}{*}{$\begin{array}{c}\text { GFIC- } \\
451\end{array}$} & $\begin{array}{c}0,0709 \\
(20- \\
55 \%) \\
\end{array}$ & $\begin{array}{c}0,0678 \\
(20- \\
55 \%) \\
\end{array}$ & 0,03 & 0,10 & 4,75 & 4,25 & 3 \\
\hline & $\begin{array}{c}0,087 \\
(15- \\
45 \%) \\
\end{array}$ & $\begin{array}{c}0,091 \\
(15- \\
45 \%) \\
\end{array}$ & 0,07 & 0,10 & 4,37 & 4,78 & 3 \\
\hline \multirow[t]{2}{*}{$\begin{array}{c}\text { GFIC- } \\
461 \\
\end{array}$} & $\begin{array}{c}0,1185 \\
(0-40 \%)\end{array}$ & $\begin{array}{c}0,1129 \\
(0-45 \%)\end{array}$ & 0,06 & 0,14 & 4,0 & 4,0 & 2 \\
\hline & $\begin{array}{c}0,1185 \\
(0-40 \%)\end{array}$ & $\begin{array}{c}0,1129 \\
(0-45 \%)\end{array}$ & 0,06 & 0,14 & 4,0 & 4,0 & 2 \\
\hline \multirow[t]{2}{*}{$\begin{array}{c}\text { OFIC- } \\
411\end{array}$} & $\begin{array}{c}47,43 \\
(15- \\
65 \%)\end{array}$ & $\begin{array}{c}48,79 \\
(15- \\
65 \%)\end{array}$ & 15 & 72 & 4,0 & 4,5 & 2 \\
\hline & $\begin{array}{l}35,43 \\
(20- \\
80 \%)\end{array}$ & $\begin{array}{l}43,24 \\
(20- \\
80 \%)\end{array}$ & 26 & 59 & 7,13 & 8,03 & 2 \\
\hline \multirow[t]{2}{*}{$\begin{array}{c}\text { OFIC- } \\
421\end{array}$} & $\begin{array}{c}65,22 \\
(20- \\
60 \%)\end{array}$ & $\begin{array}{l}58,05 \\
(20- \\
60 \%)\end{array}$ & 18 & 87 & 4,25 & 5,5 & 1 \\
\hline & $\begin{array}{c}77 \\
(30- \\
60 \%)\end{array}$ & $\begin{array}{c}82 \\
(30- \\
60 \%)\end{array}$ & 52,0 & 91 & 9,01 & 7,48 & 1 \\
\hline
\end{tabular}


Tabela 2: (continuação)

\begin{tabular}{|c|c|c|c|c|c|c|c|}
\hline \multirow[t]{2}{*}{ Malha } & \multicolumn{4}{|c|}{ Ganho estático } & \multicolumn{2}{|c|}{$\begin{array}{l}\text { Constante } \\
\text { de tempo }\end{array}$} & \multirow[t]{2}{*}{$\theta$} \\
\hline & $\begin{array}{c}\text { Ganho } \\
\text { descida } \\
\text { (faixa } \\
\text { MV) } \\
\end{array}$ & $\begin{array}{c}\text { Ganho } \\
\text { subida } \\
\text { (faixa } \\
\text { MV) } \\
\end{array}$ & Mín & Máx & Des. & Sub. & \\
\hline \multirow[t]{2}{*}{$\begin{array}{c}\text { AFIC- } \\
411\end{array}$} & $\begin{array}{c}0,2188 \\
(27- \\
67 \%)\end{array}$ & $\begin{array}{c}0,2535 \\
(27- \\
67 \%)\end{array}$ & 0,10 & 0,47 & 3,75 & 2,0 & 2 \\
\hline & $\begin{array}{c}0,7118 \\
(20- \\
60 \%)\end{array}$ & $\begin{array}{c}0,7380 \\
(20- \\
60 \%)\end{array}$ & 0,13 & 0,80 & 3,5 & 3,0 & 2 \\
\hline \multirow[t]{2}{*}{$\begin{array}{l}\text { AFIC- } \\
421\end{array}$} & $\begin{array}{l}0,76 \\
(10- \\
60 \%)\end{array}$ & $\begin{array}{l}0,72 \\
(10- \\
60 \%)\end{array}$ & 0,31 & 0,96 & 26,7 & 22 & 2 \\
\hline & $\begin{array}{l}0,76 \\
(10- \\
60 \%) \\
\end{array}$ & $\begin{array}{l}0,72 \\
(10- \\
60 \%) \\
\end{array}$ & 0,31 & 0,96 & 7,6 & 6,4 & 2 \\
\hline \multirow[t]{2}{*}{$\begin{array}{c}\text { AFIC- } \\
431 \\
\end{array}$} & $\begin{array}{c}0,2426 \\
(5-80 \%)\end{array}$ & $\begin{array}{c}0,2417 \\
(5-80 \%)\end{array}$ & 0,09 & 0,30 & 4,5 & 4,5 & 2 \\
\hline & $\begin{array}{l}0,26 \\
(20- \\
90 \%)\end{array}$ & $\begin{array}{l}0,25 \\
(20- \\
90 \%)\end{array}$ & 0,17 & 0,30 & 5,08 & 4,12 & 2 \\
\hline \multirow[t]{2}{*}{$\begin{array}{l}\text { AFIC- } \\
441\end{array}$} & $\begin{array}{c}0,5535 \\
(20- \\
55 \%)\end{array}$ & $\begin{array}{c}0,5595 \\
(20- \\
55 \%)\end{array}$ & 0,27 & 0,64 & 4,5 & 5,0 & 2 \\
\hline & $\begin{array}{l}0,51 \\
(10- \\
60 \%) \\
\end{array}$ & $\begin{array}{l}0,51 \\
(10- \\
60 \%) \\
\end{array}$ & 0,30 & 0,63 & 7,10 & 7,16 & 2 \\
\hline \multirow[t]{2}{*}{$\begin{array}{c}\text { AFIC- } \\
451\end{array}$} & $\begin{array}{c}0,1270 \\
(0-60 \%)\end{array}$ & $\begin{array}{c}0,1241 \\
(10- \\
70 \%) \\
\end{array}$ & 0,04 & 0,17 & 5,0 & 5,0 & 2 \\
\hline & $\begin{array}{c}0,15 \\
(5-55 \%) \\
\end{array}$ & $\begin{array}{c}0,16 \\
(5-55 \%) \\
\end{array}$ & 0,07 & 0,23 & 5,61 & 4,06 & 2 \\
\hline \multirow[t]{2}{*}{$\begin{array}{l}\text { AFIC- } \\
461\end{array}$} & $\begin{array}{c}0,2343 \\
(10- \\
60 \%) \\
\end{array}$ & $\begin{array}{c}0,2675 \\
(10- \\
60 \%) \\
\end{array}$ & 0,19 & 0,32 & 4,75 & 2,5 & 1 \\
\hline & $\begin{array}{c}0,2343 \\
(10- \\
60 \%)\end{array}$ & $\begin{array}{c}0,2675 \\
(10- \\
60 \%)\end{array}$ & 0,19 & 0,32 & 4,75 & 2,5 & 1 \\
\hline
\end{tabular}

\subsection{Malhas de Temperatura}

\subsubsection{Modelos da Dinâmica Dominante}

De forma semelhante às malhas de vazão, foram realizados testes em malha aberta nas malhas de temperatura com o intuito de estimar parâmetros para suas funções de transferência. Essas foram aproximadas como sendo de primeira e de segunda ordem sobre-amortecidas com atraso puro de tempo. Dessa maneira, um procedimento de três passos também foi adotado para as malhas de temperatura.

O primeiro passo consiste em realizar testes ao degrau de acordo com o perfil mostrado na Figura 7(a), ou seja, um degrau de subida de $10 \%$, seguido de um de descida de $20 \%$ e de outro de subida de $10 \%$, na variável manipulada para cada uma das 6 malhas de temperatura. Os seguintes cuidados devem ser tomados durante a realização dos testes: (i) a variável manipulada da malha em questão deve ser colocada num valor inicial próximo a 50\%; (ii) as variáveis manipuladas das demais zonas devem permanecer constantes durante todo teste (ou seja, também devem estar em modo manual); (iii) e todas as malhas de vazão devem ser colocadas em automático com as novas sintonias propostas neste trabalho. A Figura 7 mostra os dados obtidos durante o teste realizado na malha TIC451.
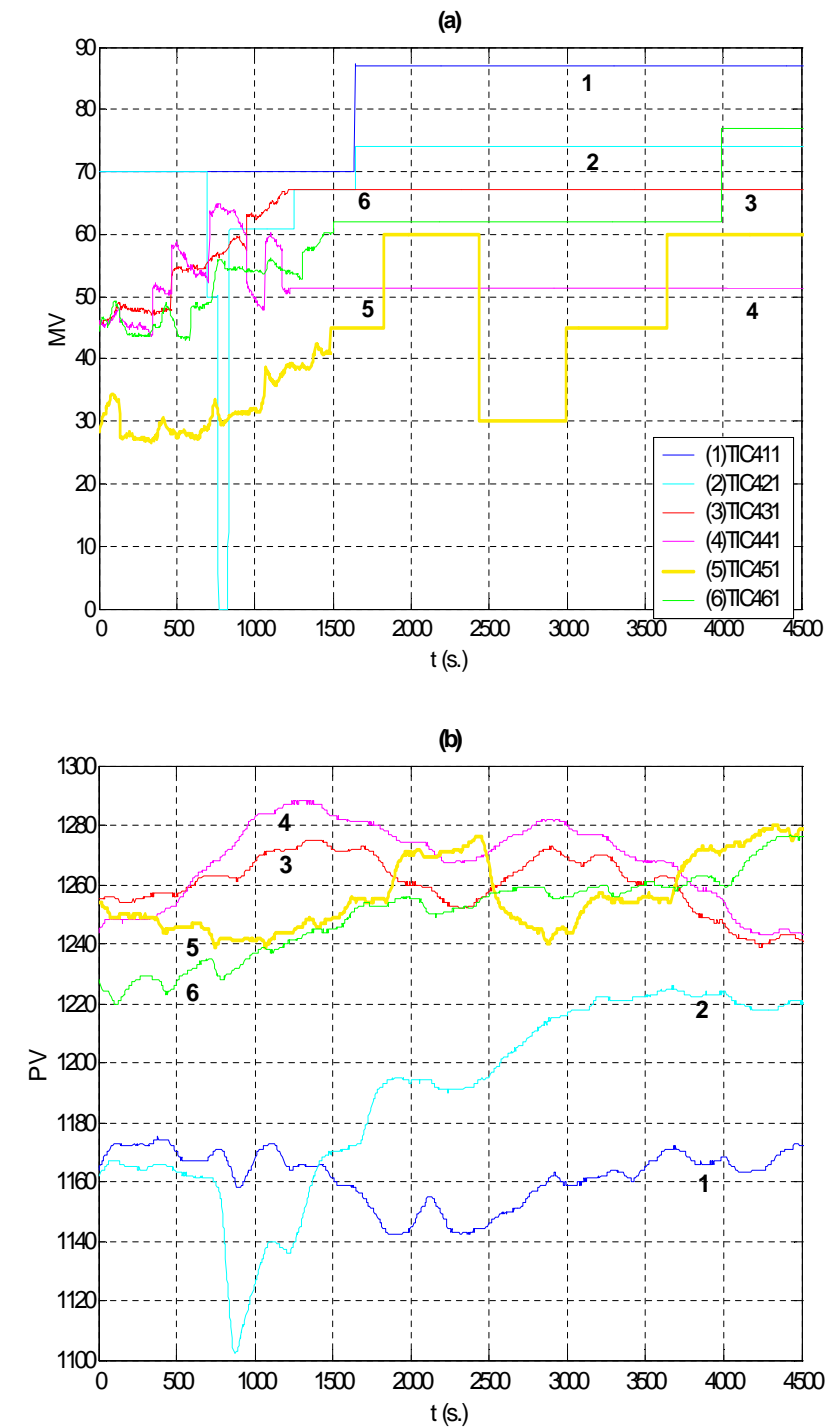

Figura 7: Dados de MV e PV de todas as malhas de temperatura para o teste realizado a fim de modelar a malha de temperatura do TIC 451. 
Em seguida, são obtidos modelos a partir do método da resposta complementar, para cada um dos degraus aplicados durante o teste descrito no parágrafo anterior. A Tabela 3 apresenta os valores obtidos. Em geral, conforme sugere a simulação dos modelos (Tabela 3) na Figura 8, os valores de ganho, constantes de tempo e tempo morto resultantes são consistentes entre si.

O último passo consiste em encontrar um modelo médio capaz de representar as características dinâmicas dominantes de cada malha de temperatura. A equação (1) constitui o modelo médio da malha TIC451 usada como exemplo nesta seção. Ela foi definida a partir dos quatro modelos da Tabela 3. O ganho de 1,0235 corresponde à média dos ganhos dos quatro testes de resposta ao degrau. Escolheu-se o tempo morto de 22 segundos porque três modelos atingiram um valor muito próximo a este. Já as constantes de tempo equivalem às do modelo $s 2$. Tal escolha é justificada pela semelhança destes valores com seus correspondentes do modelo $s 3$. A partir destes resultados, pode-se vislumbrar a dificuldade em se modelar as malhas de temperatura: os ganhos são variáveis assim como as constantes de tempo. Note que, na descida, o sistema é mais lento, o que caracteriza um padrão comum de sistemas térmicos

$$
G_{T I C 451}(s)=\frac{1,0235 e^{-22 s}}{(45,7 s+1)(24,9 s+1)} .
$$

O procedimento supracitado foi aplicado a todas as malhas do Forno 4 e os modelos a partir dele obtidos encontram-se na Tabela 4 (ano 2003). É importante comentar que, no primeiro momento, que terminou em dezembro de 2003, foram modeladas somente as malhas de temperatura das zonas de aquecimento e encharque.

Num segundo momento, o qual ocorreu após a reforma do forno, essas malhas foram remodeladas e as da zona de préaquecimento foram modeladas pela primeira vez (agosto de 2004). Foram obtidos modelos de primeira ordem com atraso puro de tempo utilizando a estimação dos parâmetros via mínimos quadrados. A adoção desse método permitiu a consideração dos efeitos de perturbação na dinâmica das malhas

Tabela 3: Parâmetros dos modelos de segunda ordem estimados para a malha TIC451.

\begin{tabular}{|l|l|l|l|l|}
\hline Degrau & $\begin{array}{l}\text { K } \\
\left({ }^{\circ} \mathbf{C} / \%\right)\end{array}$ & $\tau_{1}(\mathbf{s})$ & $\tau_{2}(\mathbf{s})$ & $\theta(\mathbf{s})$ \\
\hline s1 (MV = 45 a 60\%) & 1,0515 & 31,7 & 14,9 & 22 \\
\hline d1 (MV = 60 a 30\%) & 1,0211 & 71,1 & 14,2 & 20 \\
\hline s2 (MV = 30 a 45\%) & 0,8328 & 45,7 & 24,9 & 33 \\
\hline s3 (MV = 45 a 60\%) & 1,1885 & 47,1 & 22,0 & 22 \\
\hline
\end{tabular}

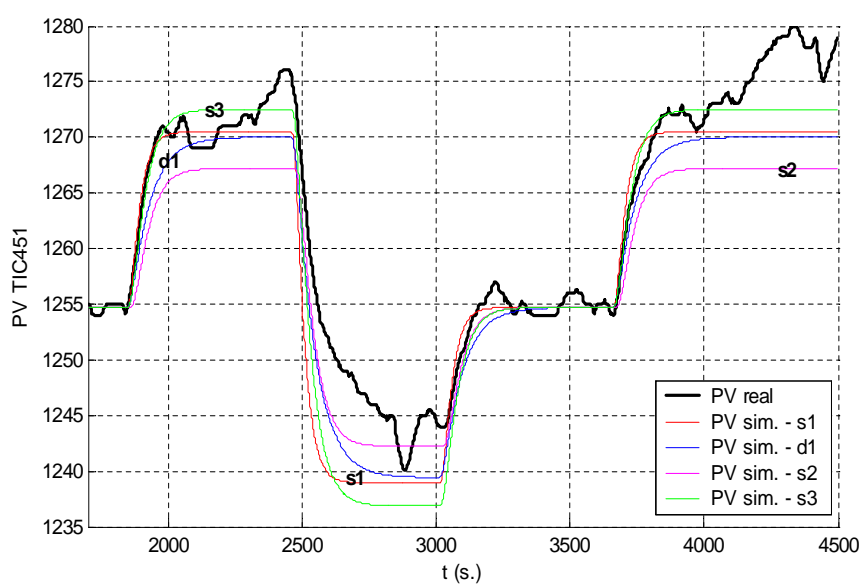

Figura 8: Simulação dos modelos da Tabela 3 para a malha TIC451.

de temperatura. As definições necessárias para utilização da técnica de mínimos quadrados, como período de amostragem e atraso máximo dos regressores, foram feitas utilizandose as informações previamente adquiridas no primeiro momento (ano 2003) e, na análise das variáveis envolvidas via testes de correlação cruzada. Conhecimento a priori do processo foi utilizado para reduzir o efeito conhecido de certas variáveis, visando melhorar a qualidade do modelo derivado pelo método dos mínimos quadrados. Dessa forma, a medida que relações de causa e efeito de certas variáveis eram determinadas, os efeitos já modelados eram retirados dos dados e uma nova matriz de regressores foi montada correlacionando a próxima variável de maior importância (conhecimento $a$ priori do processo). Outros testes foram realizados nas malhas de temperatura não somente em malha aberta, mas também em malha fechada, para estimação dos parâmetros.

\subsubsection{Modelos de Perturbação}

Dado que a classe de modelos identificados da Seção 3.2.1 não consegue explicar o comportamento dinâmico da temperatura de cada zona de maneira satisfatória, faz-se necessário buscar modelos complementares que considerem outras variáveis com forte influência sobre a temperatura da zona. Para isso, é considerado individualmente o efeito da variável de maior influência até a de menor influência. Assim, determina-se, por exemplo, para uma dada zona, a influência da temperatura de outra zona, e/ou da temperatura da placa (a qual é calculada pelo computador de processo de nível 2) na temperatura da zona.

Para exemplificar, é apresentado o procedimento utilizado na zona do pré-aquecimento superior para determinação dos modelos de perturbações. Tais modelos tratam do efeito da temperatura da placa e do efeito de acoplamento das zonas 

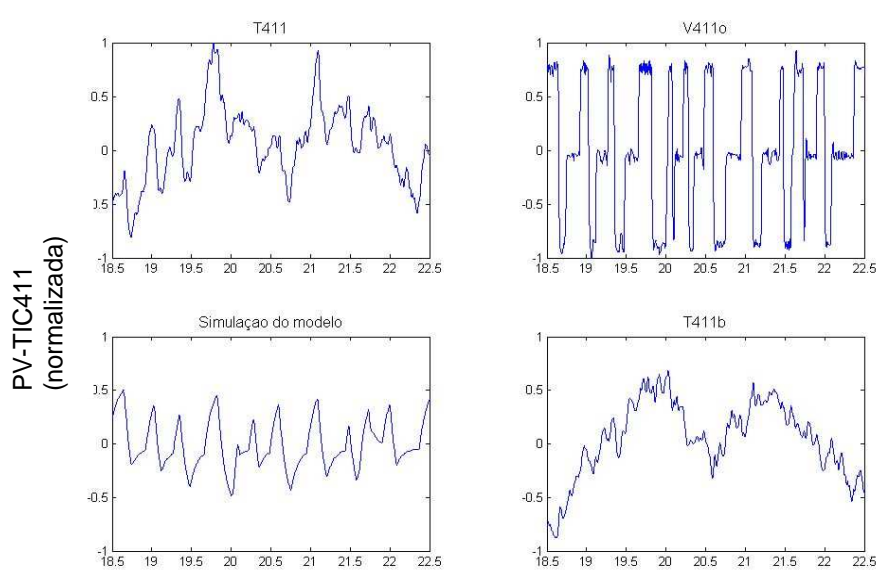

$\mathrm{t}(\mathrm{h})$

Figura 9: Eliminação do efeito da vazão de combustível (V411o), na temperatura da zona (T411). A escala vertical encontra-se normalizada.

421 e 431 com a zona 411. Sendo assim, o primeiro passo consiste em eliminar o efeito (previamente modelado conforme procedimento da Seção 3.2.1) da vazão de combustível da própria zona (V411o) em sua temperatura. Esse passo equivale simplesmente a retirar do resultado da simulação do modelo obtido a influência da variável V411o, resultando numa variável que foi chamada T411b, apresentada na Figura 9. O gráfico superior esquerdo mostra a temperatura da zona, T411. Do seu lado direito é traçado o gráfico de V411o, variável manipulada de combustível em questão. Já no gráfico inferior esquerdo, vê-se a simulação do modelo obtido e, finalmente, no último gráfico é traçada a T411b. Comparandose os gráficos de T411 e T411b, observa-se que as variações rápidas foram realmente atenuadas, conforme esperado.

Para a escolha da próxima variável cujo efeito deve ser modelado, leva-se em consideração aquela cujo efeito parece ser mais significativo. Tal decisão é tomada a partir de conhecimento a priori do processo. Para a zona do pré-aquecimento, parte-se do princípio que a influência da temperatura de entrada das placas é maior que o efeito da temperatura das zonas vizinhas. Além disso, define-se que seja modelado somente o efeito da diferença entre o resíduo da temperatura da zona, T411b, e a temperatura de enfornamento das placas. Essa variável é referida como DifTemp, na equação (2). A temperatura de enfornamento da placa é medida na mesa de enfornamento, antes da placa ser enfornada e corresponde à média das temperaturas das últimas placas carregadas em cada uma das duas alas do forno. Essa variável é referida como temperatura de enfornamento média (TempEnfMed) na equação (2)
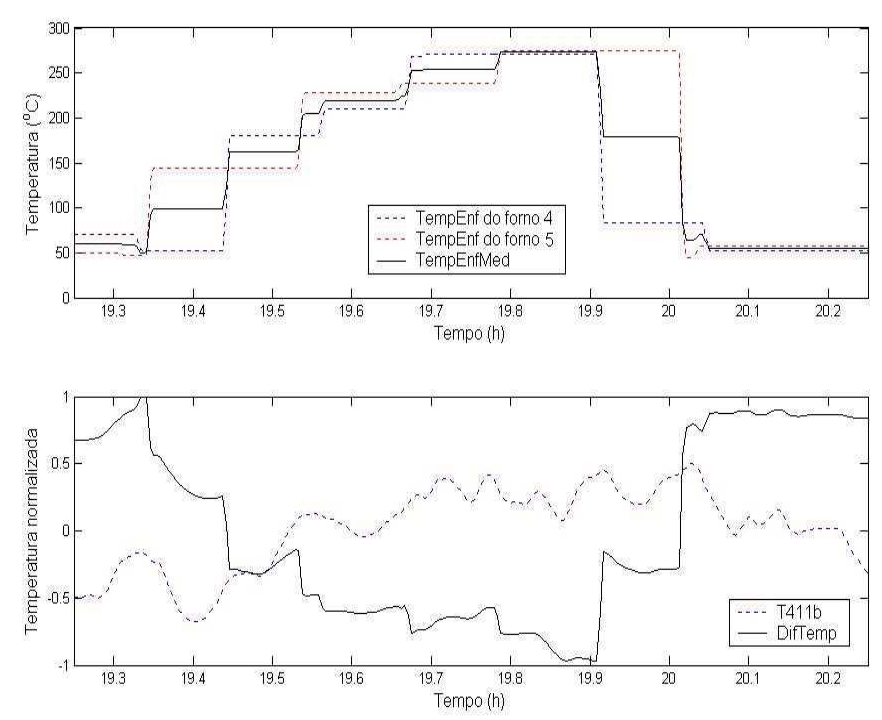

Figura 10: Janela de dados utilizada na modelagem do efeito da temperatura de entrada das placas na temperatura da zona 411.

$$
\text { DifTemp }=\text { T411b }- \text { TempEnfMed. }
$$

A Figura 10 mostra, no gráfico superior, o cálculo da temperatura média de enfornamento. No gráfico inferior, a variável DifTemp é sobreposta a T411b. Foi escolhida a janela de dados de 19:15 às 20:15 por esta apresentar uma clara correlação entre as duas variáveis em questão. Para este modelo, espera-se um ganho negativo pois a tendência das temperaturas das placas é absorver o calor do forno, considerando que o calor sempre flui da temperatura mais alta (temperatura da zona do forno, entre $1180 \mathrm{e} 1280^{\circ} \mathrm{C}$ ) para a temperatura mais baixa (temperatura da placa, normalmente inferior a $800^{\circ} \mathrm{C}$ ).

O atraso puro de tempo é determinado diretamente pelo cálculo da correlação cruzada entre T411b e DifTemp. Assim, foi indicado um atraso de aproximadamente 29 amostragens, isto é, 435s. Assim, o atraso puro de tempo é notavelmente maior do que o atraso observado entre a vazão de combustível com a temperatura da zona. Ou seja, quando uma placa é enfornada, acredita-se que somente depois de 435 segundos começa-se a perceber sua influência na temperatura da zona do forno.

O modelo determinado é mostrado na equação (3), o qual relaciona a diferença de temperatura entre as placas enfornadas $\left(\mathrm{em}^{\circ} \mathrm{C}\right) \mathrm{com}$ a temperatura da zona $411\left(\mathrm{em}{ }^{\circ} \mathrm{C}\right)$, o que torna o ganho, nesta equação, uma variável adimensional

$$
G_{\text {DifTemp }}(s)=\frac{-0,14 e^{-435 s}}{395 s+1}
$$




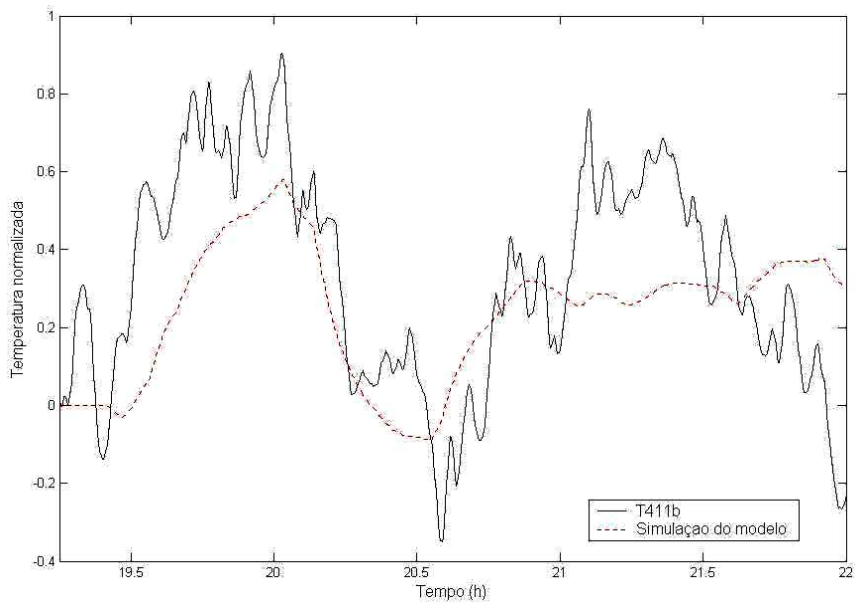

Figura 11: Simulação do modelo obtido para a influência da DifTemp na T411b.

Para validação desse modelo, o mesmo é simulado, com a massa de dados correspondente ao período de 19 às 22 horas na Figura 11. Como não é possível explicar todos os efeitos com a modelagem da temperatura de entrada da placa, a simulação do modelo sugere que ainda devem restar outras variáveis que interferem na temperatura da zona.

$\mathrm{Na}$ etapa seguinte, considera-se que a influência da temperatura da zona inferior do pré-aquecimento é maior e mais rápida que a da temperatura da zona de aquecimento superior. Assim, esse modelo a ser determinado, relaciona a temperatura do pré-aquecimento superior com a temperatura do préaquecimento inferior. Semelhante à determinação do modelo da equação (3), deve-se eliminar o efeito da DifTemp na $\mathrm{T} 411 \mathrm{~b}$, resultando numa variável que é chamada T411c (Figura 12). Comparando-se os gráficos de T411b e T411c, observa-se que as variações rápidas são atenuadas no gráfico que apresenta a variável T411c. Ou seja, os efeitos das perturbações são determinados de forma independente.

A temperatura da zona do pré-aquecimento inferior, chamada de T421, é utilizada na montagem da matriz de regressores, junto com a variável T411c (que representa a parte da T411, excluindo os efeitos da vazão de combustível da própria zona (V411o) e da temperatura das placas de entrada (DifTemp)). Tais dados são mostrados na janela de 18:20 às 20:30 da Figura 13. Estes dados, devidamente tratados, são utilizados para montar a matriz de regressores para estimação dos parâmetros pelo método dos mínimos quadrados. Os parâmetros da equação (4) relacionam a temperatura da zona $421\left({ }^{\circ} \mathrm{C}\right)$ com a temperatura da zona $411\left({ }^{\circ} \mathrm{C}\right)$

$$
G_{T 411-T 421}(s)=\frac{1,30 e^{-360 s}}{360 s+1} .
$$
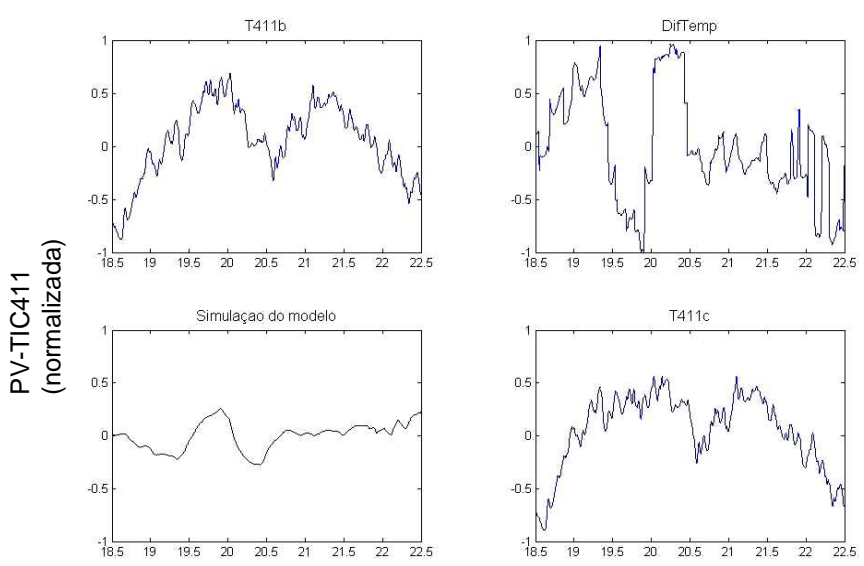

t (h)

Figura 12: Eliminação do efeito da DifTemp na T411b.
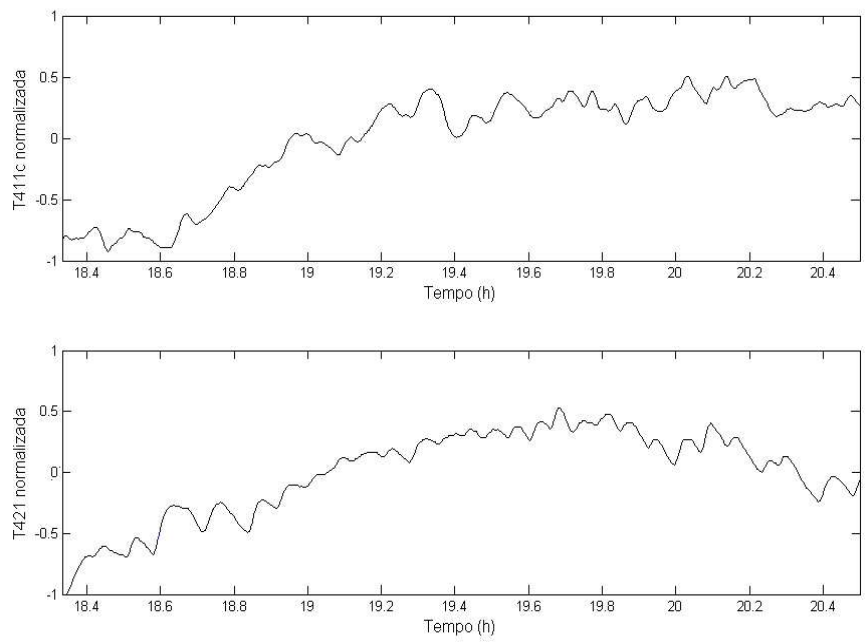

Figura 13: Dados no intervalo utilizado para modelagem do efeito da T421 na T411.

Para validação de todos os modelos estimados (equações (1) a (4)), a fim de sugerir que os efeitos de perturbação escolhidos são representativos, é apresentada a Figura 14. Os pequenos desvios observados, podem ser atribuídos aos efeitos de outras perturbações que não foram modeladas, como a abertura de portas, pressão interna e o pitch. ${ }^{2}$

Ao validar o modelo (4) usando toda a massa de dados (e não apenas os dados restritos à janela escolhida para obtenção de parâmetros deste modelo), observou-se que, com os modelos até então identificados, não seria possível explicar completamente o comportamento do sistema (expresso nos dados). Optou-se então por usar outras variáveis como entradas (perturbações) do processo e determinar suas relações

\footnotetext{
${ }^{2} \mathrm{O}$ termo pitch refere-se ao intervalo médio de tempo compreendido entre o desenfornamento de duas placas.
} 


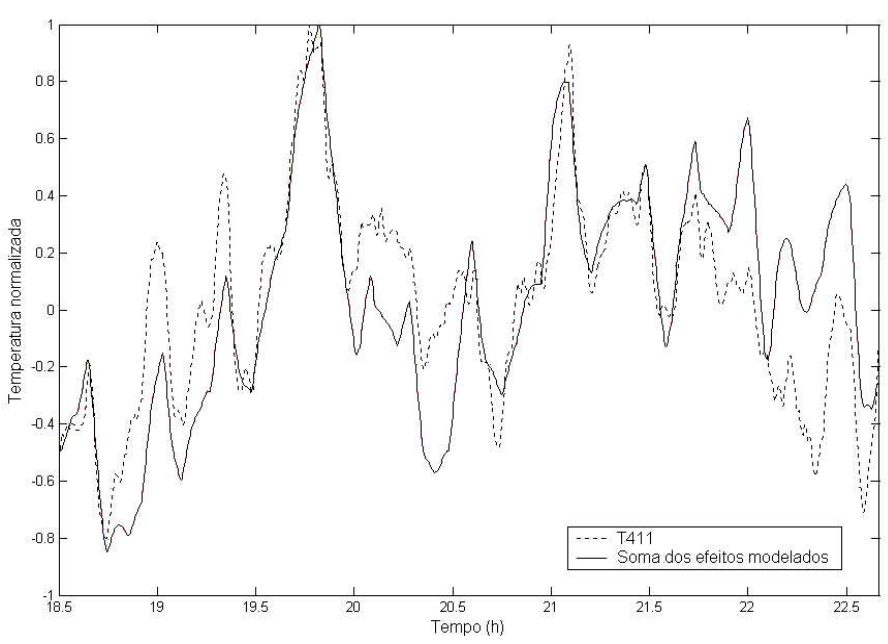

Figura 14: Soma dos efeitos modelados para a temperatura do pré-aquecimento superior (validação do modelo completo).

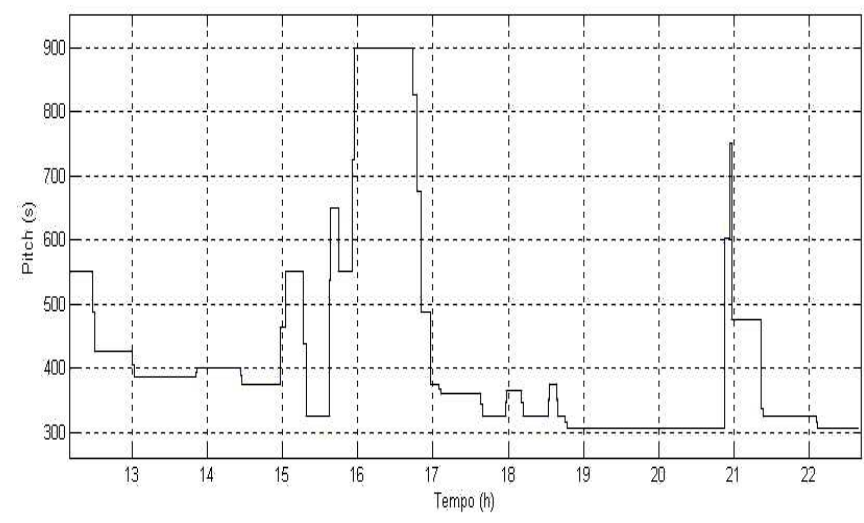

Figura 15: Perfil do pitch durante o teste realizado para a zona 411.

com a saída.

Por exemplo, comparando-se o perfil do pitch durante o período completo, mostrado na 15 , com a curva simulada da Figura 14, observa-se que o intervalo escolhido para o traçado da maioria dos gráficos (a partir das 18:30) correspondeu a um período em que não são observadas grandes variações do pitch. Isto mostra que a escolha das janelas de dados para modelagem foi adequada. No entanto, nos instantes de 18:30 às 19:30 e 21:30 as 22:30, quando há uma certa variação no pitch, observa-se uma diferença mais notável entre os dados coletados T411 e a curva simulada dos efeitos modelados.

O procedimento em discussão na presente seção foi aplicado a todas as malhas de temperatura do Forno 4 e os modelos a partir dele obtidos encontram-se resumidos na Tabela 4 (ano de 2004) e Tabela 5. Durante esta segunda etapa de modela- gem (que terminou em dezembro de 2004), foram modeladas todas as malhas de temperatura das zonas.

Pela análise da Tabela 4, pode-se notar que os ganhos das zonas inferiores do forno são maiores que os ganhos das correspondentes superiores. Este resultado é coerente com o fato de que as vazões máximas de combustível das zonas inferiores são maiores que as das superiores. Além disso, notam-se valores razoavelmente discrepantes nos parâmetros dos modelos 2003 e 2004, principalmente, com relação aos valores de ganho. Tais diferenças reforçam as dificuldades em se encontrar modelos lineares invariantes no tempo conforme foi relatado na Seção 1.

Tabela 4: Parâmetros dos modelos obtidos para as malhas de temperatura-2003/2004.

\begin{tabular}{|c|c|c|c|c|c|c|c|}
\hline \multirow{2}{*}{ Malha } & & $\mathbf{4 I C}$ & TIC & TIC & TIC & TIC & TIC \\
\hline \multirow{4}{*}{$\begin{array}{c}\text { Modelo } \\
2003\end{array}$} & $\begin{array}{c}\mathrm{K} \\
\left({ }^{o} \mathrm{C} / \%\right)\end{array}$ & - & - & 0,75 & 1,48 & 1,19 & 1,20 \\
\cline { 2 - 8 } & $\tau_{1}(s)$. & - & - & 88,5 & 87,5 & 45,7 & 86,8 \\
\cline { 2 - 8 } & $\tau_{2}(s)$. & - & - & 61,7 & 59,3 & 24,9 & 34,9 \\
\cline { 2 - 8 } & $\theta(s)$. & - & - & 55 & 65 & 33 & 51 \\
\hline \multirow{2}{*}{$\begin{array}{c}\text { Modelo } \\
2004\end{array}$} & $\begin{array}{c}\mathrm{K} \\
\left({ }^{o} \mathrm{C} / \%\right)\end{array}$ & 0,11 & 0,12 & 0,66 & 0,74 & 2,80 & 3,84 \\
\cline { 2 - 8 } & $\tau_{1}(s)$. & 365 & 525 & 106 & 122 & 88,5 & 90 \\
\cline { 2 - 8 } & $\theta(s)$. & 30 & 30 & 55 & 55 & 55 & 55 \\
\hline
\end{tabular}

\subsubsection{Análise da Matriz de Ganhos Relativos}

$\mathrm{Na}$ literatura, o acoplamento entre as zonas de um forno de reaquecimento é citado por (Kusters e Van Ditzhuijzen, 1994; Wang et al., 1999b; Ko et al., 2000). Segundo esses autores, a queima de combustível na zona de encharque superior acarreta na mudança de temperatura de outras zonas também, como a de encharque inferior e a de aquecimento superior. Essa última, por sua vez, interfere no comportamento dinâmico das zonas de aquecimento inferior e préaquecimento superior. Dessa maneira, considera-se que há um gradiente de temperatura, na direção horizontal, da zona de desenfornamento para a de enfornamento e também devese considerar trocas de calor entre as partes superior e inferior de uma mesma zona. No entanto, não são apresentados métodos numéricos que quantifiquem tais interações entre as zonas do forno.

Neste trabalho, para avaliar o grau de acoplamento entre as zonas do forno e para, eventualmente, investigar a utilização de alguma estratégia de desacoplamento para atenuar seus efeitos na estabilidade do sistema de controle, é utilizada a 
Tabela 5: Parâmetros dos modelos de perturbação estimados para as malhas de temperatura via mínimos quadrados por zona.

\begin{tabular}{|c|c|c|c|c|}
\hline Zona & $\begin{array}{l}\text { Variável de } \\
\text { influência }\end{array}$ & $\begin{array}{c}\mathbf{K} \\
\left({ }^{o} \mathbf{C} / \%\right) \\
\end{array}$ & $\tau(\mathbf{s})$ & $\theta(\mathbf{s})$ \\
\hline \multirow{4}{*}{$\begin{array}{c}\text { Pré- } \\
\text { Aquecimento } \\
\text { superior(411) }\end{array}$} & TIC 411 & 1,53 & 350 & 30 \\
\hline & Temp. placa & $-0,14$ & 395 & 435 \\
\hline & TIC $421 / 411$ & 1,30 & 360 & 360 \\
\hline & TIC $431 / 411$ & 0,32 & 850 & 100 \\
\hline \multirow{5}{*}{$\begin{array}{c}\text { Pré- } \\
\text { Aquecimento } \\
\text { inferior } \\
(421)\end{array}$} & TIC 421 & 2,11 & 510 & 30 \\
\hline & Temp. placa & $-0,14$ & 395 & 435 \\
\hline & TIC $441 / 421$ & 1,30 & 360 & 360 \\
\hline & TIC 431/421 & 0,5 & 420 & 410 \\
\hline & TIC $411 / 421$ & 0,05 & 850 & 100 \\
\hline \multirow{4}{*}{$\begin{array}{c}\text { Aquecimento } \\
\text { superior } \\
(431)\end{array}$} & TIC 431 & 1,39 & 120 & 55 \\
\hline & TIC 441/431 & 1,10 & 385 & 55 \\
\hline & TIC451/431 & 1,38 & 738 & 300 \\
\hline & TIC $411 / 431$ & 0,44 & 290 & 190 \\
\hline \multirow{3}{*}{$\begin{array}{c}\text { Aquecimento } \\
\text { inferior } \\
(441)\end{array}$} & TIC 441 & 1,36 & 172 & 55 \\
\hline & TIC 431/441 & 1,20 & 100 & 280 \\
\hline & TIC461/441 & 1,25 & 816 & 600 \\
\hline \multirow{2}{*}{$\begin{array}{c}\text { Encharque } \\
\text { superior } \\
(451)\end{array}$} & TIC 451 & 0,69 & 135 & 55 \\
\hline & TIC 461/451 & 0.53 & 196 & 120 \\
\hline \multirow{2}{*}{$\begin{array}{l}\text { Encharque } \\
\text { inferior } \\
(461)\end{array}$} & TIC 461 & 0,83 & 168 & 55 \\
\hline & TIC 451/461 & 0,08 & 102 & 220 \\
\hline
\end{tabular}

técnica conhecida como matriz de ganhos relativos (MGR) ${ }^{3}$ (Bristol, 1966; Seborg et. al., 1989; Shinskey, 1996; Jota, 1998). A MGR foi inicialmente proposta como uma medida do grau de interação em baixas frequências de sistemas com natureza multivariável. Adicionalmente, o método proporciona uma indicação do emparelhamento mais efetivo das variáveis controladas e manipuladas.

Como as informações necessárias para o cálculo da MGR referem-se a ganhos estáticos do sistema e, esses podem ser obtidos a partir de funções de transferência, aplicou-se tal ferramenta ao forno de reaquecimento em estudo. Os ganhos estáticos podem ser extraídos diretamente das funções de transferência montadas utilizando-se os parâmetros esti-

\footnotetext{
${ }^{3}$ MGR é o acrônimo que se refere ao equivalente em inglês, RGA, Relative Gain Array.
}

mados da Tabela 5. Assim, a equação (5) representa a matriz de ganhos estacionários do sistema

O cálculo da MGR é baseado no conceito de ganho relativo. O ganho relativo $\lambda_{i j}$ de uma variável controlada, $\mathrm{PV}_{i}$, e uma variável manipulada, $\mathrm{MV}_{j}$, é definido, para esse forno, como sendo uma relação de seis ganhos estáticos:

$$
\begin{gathered}
{\left[\begin{array}{c}
\mathrm{PV}_{411} \\
\mathrm{PV}_{421} \\
\mathrm{PV}_{431} \\
\mathrm{PV}_{441} \\
\mathrm{PV}_{451} \\
\mathrm{PV}_{461}
\end{array}\right]=} \\
{\left[\begin{array}{cccccc}
1,53 & 1,30 & 0,32 & 0 & 0 & 0 \\
0,05 & 2,11 & 0,50 & 1,30 & 0 & 0 \\
0,44 & 0 & 1,39 & 1,09 & 1,38 & 0 \\
0 & 0 & 1,20 & 1,36 & 0 & 0,26 \\
0 & 0 & 0 & 0 & 0,69 & 0,53 \\
0 & 0 & 0 & 0 & 0,08 & 0,83
\end{array}\right]\left[\begin{array}{l}
\mathrm{MV}_{411} \\
\mathrm{MV}_{421} \\
\mathrm{MV}_{431} \\
\mathrm{MV}_{441} \\
\mathrm{MV}_{451} \\
\mathrm{MV}_{M 61}
\end{array}\right]}
\end{gathered}
$$

$\lambda_{i j}=\frac{\left(\partial P V_{i} / \partial M V_{j}\right) M V}{\left(\partial P V_{i} / M V_{j}\right) P V}=\frac{\text { ganho_em_malha_aberta }}{\text { ganho_em_malha_fechada} .}$

Na equação (6), a derivada do numerador representa o ganho em malha aberta entre $\mathrm{PV}_{i}$ e $\mathrm{MV}_{j}$ com as demais variáveis manipuladas mantidas constantes. De forma similar, o termo no denominador, representa o ganho em malha fechada, com todas as variáveis controladas, exceto $\mathrm{PV}_{i}$, mantidas constantes. Portanto, estes ganhos podem ser calculados pela equação (6), ou pode-se utilizar a expressão:

$$
\lambda_{i j}=K_{i j} *\left(K^{-1}\right)_{i j}^{T},
$$

em que $\lambda_{i j}$ representa cada elemento da matriz MGR dos ganhos em malha aberta $\mathrm{K}_{i j}$ e a multiplicação, indicada na equação (7), é feita elemento a elemento. Utilizando-se a equação (7) obtida a matriz de ganhos relativos do sistema em estudo:

$$
\Lambda=\begin{array}{cccccc}
M 1 & M 2 & M 3 & M 4 & M 5 & M 6 \\
\mathrm{C} 1 \\
\mathrm{C} 2 \\
\mathrm{C} 3 \\
\mathrm{C} 4 \\
\mathrm{C} 5 \\
\mathrm{C} 6
\end{array}\left[\begin{array}{cccccc}
2.01 & -0,58 & -0,43 & 0 & 0 & 0 \\
-0,04 & 1,58 & 0,42 & -0,95 & 0 & 0 \\
-0,97 & 0 & 6,39 & -4,43 & 0 & 0 \\
0 & 0 & -5,38 & 6,38 & 0 & 0 \\
0 & 0 & 0 & 0 & 1,08 & -0,08 \\
0 & 0 & 0 & 0 & -0,08 & 1,08
\end{array}\right]
$$


As seguintes variáveis do processo que influenciam diretamente o grau de acoplamento entre as zonas do forno são consideradas: a temperatura do gás queimado, as temperaturas das zonas e a pressão interna do forno. Dentre essas, as temperaturas das zonas do forno foram particularmente consideradas na modelagem do processo e na definição da matriz de ganhos relativos.

Antes de fazer uma análise da matriz, pela interpretação do comportamento físico do processo, pode-se fazer as seguintes afirmações:

- A influência da zona inferior na zona superior é maior que a influência da zona superior na inferior. Por exemplo, quando o forno é aceso, inicia-se a queima na zona inferior, entendendo-se que o calor fluirá para a zona superior, proporcionando o aquecimento adequado dos refratários.

- A influência das zonas no sentido do desenfornamento para o enfornamento é maior que a influência no sentido contrário. Essa influência ocorre sempre nas zonas que estão mais próximas. Porém a influência do préaquecimento no aquecimento para o forno estudado é maior que a influência do aquecimento para o encharque devido a dois fatores principais. Primeiro, por causa das paredes de contenção na zona pré-aquecimento superior e inferior, que diminuem a velocidade do arraste de calor direto para o canal da fumaça, afetando os fatores de transmissão de calor relativo a convecção de calor. Em segundo lugar, tal comportamento deve-se a posição do queimador dentro do forno. Ou seja, na zona de encharque e pré-aquecimento o fluxo de calor ocorre no sentido do desenfornamento e, no aquecimento, está no sentido do enfornamento.

Analisando os resultados obtidos pela MGR pelo valor de $\lambda$, na equação (8), e considerando que $C$ é a variável controlada e M a variável manipulada, é possível argumentar que:

- emparelhamento atual das variáveis está bem adequado. Porém, recomenda-se ainda o emparelhamento das variáveis C2-M3 $(\lambda=0,42)$, pois trata-se de um valor positivo que indica acoplamento significativo;

- deve-se projetar desacopladores para as seguintes situações: C1-M2 $(\lambda=-0,58), \mathrm{C} 1-\mathrm{M} 3(\lambda=-0,43), \mathrm{C} 2-\mathrm{M} 1$ $(\lambda=-0,04), \mathrm{C} 2-\mathrm{M} 4(\lambda=-0,95), \mathrm{C} 3-\mathrm{M} 1(\lambda=-0,97), \mathrm{C} 3-\mathrm{M} 4$ $(\lambda=-4,43)$, C4-M3 $(\lambda=-5,38)$.

A necessidade dos desacopladores aplica-se mais no sentido do desenfornamento para enfornamento do forno, exceto na zona do encharque. Observou-se uma influência forte da zona de aquecimento $(\lambda=-5,38)$ superior na inferior e viceversa $(\lambda=-4,43)$. O projeto de desacoplador estático seria recomendado nessas condições, pois o mesmo pode ser visto como um compensador antecipatório cuja função de transferência é apenas um ganho estático. Porém na zona de aquecimento é possível que o projeto de desacopladores não resolva integralmente este problema. O mais recomendável seria aplicar o controle multivariável devido à influência ter sido muito negativa ( $\lambda=-5,38$ e $\lambda=-4,43)$ e próximo da influência da MV da zona nela mesma.

Na presente avaliação, não é analisada a interação dinâmica entre as malhas da planta. Para isso, outra técnica de análise deve ser empregada. Para análise estática, considerou-se satisfatório o emparelhamento sugerido pela matriz estática (tendo em vista que, na maior parte do tempo, o processo as malhas de temperatura estão predominantemente em modo de regulação). Além disso, não há interesse em estudar, simular e implementar o projeto dos desacopladores para condições não-estacionárias. A informação nova e importante para o controle refere-se às interações que afetam o projeto dos controladores. Além disto, somente com os sistemas de controle devidamente sintonizados, talvez, não seja possível eliminar a falta e o excesso de calor no forno, devido aos efeitos de acoplamentos existentes, sugeridos pela MGR refletido nas temperaturas controladas das zonas.

\subsection{Considerações gerais sobre modela- gem do forno}

Não obstante as grandes dificuldades encontradas durante o desenvolvimento do trabalho, a modelagem do forno de reaquecimento de placas da linha de tiras a quente da Usiminas apresentou resultados satisfatórios. As principais dificuldades estão relacionadas aos efeitos de perturbação e interação entre as malhas, a realização prática de testes adequados (alguns que afetam a qualidade do aquecimento da placa), a definição adequada das variáveis a serem consideradas na matriz de regressores (entradas e saídas) para estimação de parâmetros por mínimos quadrados e a definição da melhor representação dos dados para identificação. Em relação à modelagem utilizando a resposta ao degrau para temperatura, a maior dificuldade é escolher as variações que representam a característica dominante do processo.

Para modelagem matemática do forno, partiu-se do conhecimento a priori do processo para aplicação das técnicas de identificação de sistemas. Isso permitiu que se encontrassem modelos mais precisos para o processo, e posteriormente, a definição e a sintonia das estratégias de controle.

Tendo em vista as dificuldades encontradas para obtenção dos modelos do forno e a ocorrência de casos em que ficou explícita a necessidade de informações complementares ca- 
pazes de explicar o comportamento do processo, recomendase investigar técnicas que vêm sendo estudadas para identificação em malha fechada com o foco em controle. Uma das principais motivações para o uso dessas técnicas é a possível aplicação em processos industriais, aproveitando dados históricos ou através de experimentos de identificação menos onerosos quanto ao esforço de engenharia e distúrbios da produção. Entretanto, a identificação em malha fechada é ainda uma questão aberta, que requer uma adequada caracterização do seu potencial e das suas limitações. Por outro lado, para Van den Hof (1998), identificação para controle equivale a aprendizagem. Basta obter modelos mais simples (primeira ordem com tempo morto) e projetar controladores consistentes. Nesses casos, as funções de transferência devem ser obtidas em malha aberta. Do ponto de vista científico, é instigante imaginar como é possível adquirir conhecimento sobre processos em que a restrição para a experimentação é bastante grande, de forma a se poder propor estratégias que possam melhorar, de forma gradual, o seu desempenho.

\section{PROJETO DE CONTROLADORES}

Baseado nos modelos matemáticos determinados para as malhas de vazão e de temperatura, bem como nos modelos que representam o efeito da entrada de placas na zona do préaquecimento e nos modelos de perturbações das outras zonas, foram definidas novas propostas de estratégias de controle bem como realizada a ressintonia dos controladores existentes.

Para o processo em estudo, utilizaram-se controladores PI para as malhas de vazão e PID para as malhas de temperatura. Em (9), é mostrada a equação do algoritmo PID clássico no domínio de Laplace. O projeto desses controladores consiste em calcular as constantes: $K_{P}$, ganho proporcional, $T_{I}$, tempo integral e, no caso do PID, $T_{D}$, tempo derivativo

$$
M V(s)=K_{p}\left[1+\frac{1}{T_{I} s}+T_{D} s\right] E(s) .
$$

$\mathrm{Na}$ prática, os algoritmos de controle operam comumente com valores normalizados entre 0 e $100 \%$ para MV e para PV. Na indústria, é corrente usar o conceito de $B P$, banda proporcional, definida de acordo com a equação (10). No caso do sistema do forno da Usiminas, a banda proporcional é normalizada

$$
B P_{N}=\frac{\frac{100}{K_{P}}}{\frac{P V_{\max }-P V_{\min }}{100}} .
$$

O tempo integral também é conhecido por reset time e o de- rivativo por rate time. $\mathrm{O}$ parâmetro $\mathrm{T}_{I}$ corresponde ao tempo em que a parcela relativa a parte proporcional da ação de controle é duplicada. Quanto menor seu valor, mais forte é a ação integral. Já $\mathrm{T}_{D}$ equivale ao tamanho do intervalo de tempo sobre o qual estima-se a saída do processo, a fim de antecipar a ação de controle. A resposta do sistema torna-se mais rápida com o aumento de $\mathrm{T}_{D}$. Detalhes de implementação e projeto de controladores PID digitais podem ser encontrados em (Åström e Hägglund, 1995). Existem vários métodos para se fazer sintonia de controladores PID. A definição de seus parâmetros deve atingir os critérios pré-estabelecidos de precisão em estado estacionário, resposta transitória, estabilidade relativa, sensitividade, rejeição a perturbações e esforço de controle (Dorf e Bishop, 1998). Em se tratando da sintonia de controladores PID, dois paradigmas podem ser abordados.

Primeiramente, há os métodos baseados em testes em malha fechada. Nesse grupo, podem ser incluídos o método por tentativa e erro (o qual requer o entendimento de como alterações nos parâmetros do controlador influenciam na resposta do sistema e a execução de um enfadonho número de testes (Seborg et al., 1989)) e o método do período crítico (chamado de continuous cycling method por seus inventores (Ziegler e Nichols, 1942)). Esse último, apesar de sua popularidade no meio industrial, apresenta a restrição de resultar, obrigatoriamente, em respostas oscilatórias com sobressinal de 20 a 50\%. Como principal vantagem do grupo dos métodos baseados em testes em malha fechada, pode-se citar a não exigência do conhecimento do modelo da dinâmica dominante do processo. Em contrapartida, para processos muito lentos, os testes, além de numerosos, podem ser demorados. Ademais, existe o risco do processo ser levado à instabilidade.

O segundo grupo requer a determinação a priori de modelos para os sistemas onde são aplicados, principalmente, na forma de funções de transferência. Esses modelos são geralmente obtidos a partir de testes em malha aberta da resposta ao degrau. Como consequiência, incertezas no modelo podem gerar comportamento indesejado na resposta do sistema em malha fechada, sendo essa a principal desvantagem desses métodos. Esse paradigma inclui, dentre outros, os seguintes métodos: projeto baseado na curva de reação (Ziegler e Nichols, 1942); relações de Cohen-Coon; relações para minimização de índices de desempenho, como ITAE, ISE e ITSE; controle por modelo interno; e o método da síntese direta (Seborg et al., 1989). Aqui, também podem ser referenciados os métodos no domínio da frequiência, como o projeto de compensadores de atraso-avanço contínuos (Dorf e Bishop, 1998) e discretos (Phillips e Näggle, 1995).

Neste trabalho, utilizam-se os método da síntese direta e do controle por modelo interno para projeto de controladores PI 
e PID. Além da simplicidade, esses métodos apresentam a vantagem de estabelecer uma relação direta entre o modelo do processo e controlador resultante (Seborg et al, 1989).

\subsection{Malhas de Vazão}

Para o projeto dos controladores PI das malhas de vazão, buscou-se uma sintonia que reduzisse o tempo de acomodação do processo sem provocar sobressinais e que garantisse a estabilidade em malha fechada. Com isso, essa sintonia buscou reduzir a variabilidade da ação de controle, favorecendo, a médio e a longo prazo, a redução do índice de manutenção das válvulas.

A sintonia dos controladores das malhas de vazão foi realizada em dois momentos distintos. A primeira sintonia foi finalizada no final de dezembro de 2003 e a segunda no final de agosto de 2004, após a reforma do Forno 4.

A partir das funções de transferência de primeira ordem com atraso puro de tempo apresentadas na Seção 3.1, foram projetados controladores PI para as malhas de vazão de ar, gás e óleo do processo em estudo. Utilizou-se o método da síntese direta para ajuste dos valores de $\mathrm{BP}_{N}$ e $\mathrm{T}_{I}$.

Tendo em vista que foram observadas variações nos parâmetros dos modelos das válvulas em função do ponto de operação das mesmas, o cálculo dos parâmetros dos controladores foi mais conservador num primeiro momento. Ou seja, buscou-se atingir o menor ganho proporcional $\mathrm{K}_{P}$ (ou maior valor de banda proporcional $\mathrm{BP}_{N}$ ) e o maior tempo integral $\mathrm{T}_{I}$ que resultassem em um desempenho dinâmico satisfatório de cada malha de vazão. Inicialmente (sintonia de 2003), este conservadorismo foi adotado na escolha dos parâmetros do modelo de cada válvula. Por exemplo, em vez de adotar o ganho médio de descida ou de subida, $\mathrm{K}_{\text {med }}$, foi usado o maior valor de ganho de cada válvula, $\mathrm{K}_{m a ́}$, como ganho do processo a ser usado no cálculo de $\mathrm{K}_{P}$. Porém, após a nova sintonia dos controladores de temperatura realizada em 2004, essa especificação foi alterada, pois houve necessidade de aumentar a velocidade de resposta das malhas internas (malhas de vazão). Dessa maneira, adotou-se $\mathrm{K}_{m e d}$, como o ganho do processo a ser usado no cálculo de $\mathrm{K}_{P}$.

Com relação à constante de tempo $(\tau)$, dentre os valores dos modelos médios de descida e de subida, aquela de maior valor foi usada para definição do tempo integral $\mathrm{T}_{I}$. Já para cálculo do ganho proporcional $\mathrm{K}_{P}$, escolheu-se a de menor valor. As equações do método da síntese direta comprovam que estas especificações de projeto: $\mathrm{K}_{P}$ e $\mathrm{T}_{I}$ são diretamente proporcionais à constante de tempo do processo. Para exemplificar melhor, na Tabela 6, a constante de tempo para descida $\tau_{d}$ da válvula da malha AFIC451, é igual a 5,61 e, para subida $\tau_{s}$ igual a 4,06. Assim, 5,61 foi o valor usado no ajuste do tempo integral $\mathrm{T}_{I}$ e 4,06 para o cálculo do ganho proporcional.

Para definição da constante de tempo desejada em malha fechada $\tau_{M F}$, adotou-se um valor próximo à constante de tempo em malha aberta no lugar de um valor que tornasse a malha mais rápida, porém mais oscilatória. Escolheu-se então, $\tau_{M F}$ igual à soma do atraso puro de tempo $\theta$ e da maior constante de tempo entre os valores de descida $\tau_{d} \mathrm{e}$ subida $\tau_{s}$. Duas razões justificam essa opção. Primeiro, os valores de constante de tempo em malha fechada $\tau_{M F}$, assim definidos, são cerca de cinco a dez vezes menores que constante de tempo $\left(\tau_{1}\right)$ dominante da malha de temperatura correspondente, com a qual as malhas de vazão estão interligadas numa configuração em cascata. Em segundo lugar, o período de amostragem $\Delta \mathrm{T}$ mínimo aceito pelo DCS (do inglês, Distributed Control System) é de um segundo. Dessa maneira, é recomendável que $\tau_{M F}$ seja maior que cinco segundos (Phillips e Näggle, 1995). Ainda com relação a $\tau_{M F}$, que foi escolhida para as malhas de vazão de uma dada zona, a maior soma de $\tau$ e $\theta$ dentre as somas das malhas de ar, gás e óleo foi adotada. Ou seja, para quase todas as malhas de vazão de uma mesma zona foi definido o mesmo valor de $\tau_{M F}$, considerando que as malhas de combustíveis e ar, estão interligadas pela estratégia de duplo limite cruzado.

Para exemplificar, é considerada a zona 411, onde, para a malha AFIC411, $\tau_{M F} \cong 5,5$, para GFIC411, $\tau_{M F} \cong 6,7 \mathrm{e}$, para OFIC411, $\tau_{M F} \cong 10,0$. Assim sendo, $\tau_{M F}=10 \mathrm{~s}$ é o maior valor e foi o escolhido.

A Tabela 6 contém os dados usados na sintonia dos controladores PI em 2004, bem como os ajustes a partir deles obtidos. Em linhas gerais, as decisões de projeto descritas nos parágrafos anteriores foram consideradas, mas alguns ajustes finos foram realizados em algumas malhas, devido ao fato do DCS somente permitir a configuração de valores inteiros nos parâmetros. De uma maneira geral, observa-se que os tempos integrais $T_{I}$ propostos para as malhas de vazão estão entre 4 e 9 segundos, ao passo que as bandas proporcionais $B P_{N}$ não seguem valores comuns.

Na Tabela 6, também são exibidos os parâmetros originais, encontrados nos controladores PI das malhas de vazão, antes de iniciar a sintonia destas malhas. Ao comparar esses valores com os propostos, observa-se que os $T_{I}$ originais são de 1,1 a 4 vezes maiores que os novos valores sugeridos. Em relação ao ajuste efetuado em 2003 os valores originais eram de 1,7 a 6,8 vezes maiores. Sabendo que o sobredimensionamento do tempo integral resulta em uma resposta dinâmica mais lenta, os valores originais desse parâmetro são acompanhados de valores elevados de ganho proporcional (ou reduzidos de banda proporcional), numa tentativa de não deixar a resposta da malha tão lenta. Dessa maneira, os valores pro- 
postos em 2004 de $K_{P}$ são de 1,2 a 7,0 vezes menores que os originais (em termos de banda proporcional $B P_{N}$, os novos ajustes são maiores), exceto para as malhas de óleo e ar do pré-aquecimento. Apenas as sintonias propostas para as malhas de óleo e ar que, diferem das demais malhas de vazão no valor do ganho proporcional, os valores de $K_{P}$ sugeridos são maiores que os originais (ou os valores propostos de $B P_{N}$ são menores que os em uso).

Em 2003, os valores de $K_{P}$ eram de 1,4 a 9,1 vezes menores que os originais (quanto à banda proporcional $B P_{N}$, os novos ajustes são maiores), exceto para as malhas de óleo. Os valores mais discrepantes de ajuste de $B P_{N}$ ocorrem para as malhas de gás. A redução do ganho proporcional acarreta na redução da atividade dos atuadores, ou seja, espera-se um sinal de MV de menor variância. Isso porque, o sinal de erro recebido pelo controlador é multiplicado por um ganho $K_{P}$ menor. Maiores detalhes sobre a sintonia das malhas de vazão realizada em 2003 podem ser encontrados em (Teixeira, 2004).

\subsection{Malhas de Temperatura}

Para o projeto dos controladores PID e a implementação das novas estratégias de controle de temperatura, buscaram-se sintonias que minimizassem os efeitos das perturbações e os sobressinais na variável controlada, que reduzissem o tempo de resposta da planta e que garantissem a estabilidade em malha fechada. Nas especificações de projeto, visando atender aos critérios definidos, foram consideradas as variações de parâmetros dos modelos matemáticos utilizados para representar a planta em diversas condições. Dessa forma, o projeto foi conduzido na direção de ajustes mais conservadores, priorizando sempre a robustez e a estabilidade do sistema de controle.

Antes da implementação das sintonias propostas neste trabalho, uma das reclamações mais freqüentes dos operadores referia-se exatamente à incapacidade do sistema de controle de manter as temperaturas em seus respectivos setpoints, principalmente, quando o forno era alimentado por uma sequiência de placas frias. $\mathrm{O}$ mesmo era observado quando o forno era submetido a um ritmo de produção mais intenso com enfornamentos e desenfornamentos de placas mais freqüentes.

Para a zona de aquecimento, foi observado que na condição operacional de ritmo de produção intenso, ocorrem frequentes saturações na ação de controle. Em algumas situações, os sistemas de controle da zona do pré-aquecimento são retirados do modo otimizado, ficando os controladores de temperatura em modo automático, porém com o setpoint definido pelo operador. Em outras situações operacionais, os controladores de temperatura, são passados para modo manual e a variável de processo (vazão de combustível) é manualmente ajustada com a maior abertura possível, evitando-se o estrangulamento ( $100 \%$ aberta) da válvula de controle. De maneira geral, observou-se pelos diversos testes realizados que há uma ação manual preventiva do operador no forno, quando tem-se a previsão de entrada de material ou quando se altera o ritmo de produção.

Avaliando todos os modelos definidos para o forno 4 e em consonância com o principal objetivo deste trabalho, isto é, reduzir o nível de variação da variável controlada em relação a variável de referência (melhorando o desempenho da planta independente das condições operacionais), identificaram-se pelo menos quatro novas estratégias de controle que poderiam ser empregadas no processo em estudo:

- aplicação da técnica de controle chaveado na zona do pré-aquecimento, considerando que na modelagem da planta foi caracterizada a necessidade de três modelos para melhor representar esta parte do processo;

- aplicação de controle antecipatório na zona do préaquecimento, utilizando-se dos modelos de perturbação das placas nas zonas;

- emprego de preditor de Smith, na zona do encharque, considerando as funções de transferência identificadas e validadas e a relação observada entre o atraso puro de tempo e a constante de tempo e ter sido maior que 0,5 ;

- aplicação de projeto de desacopladores para a zona do aquecimento, considerando o forte acoplamento existente.

Vale destacar que, simplesmente, com os novos projetos dos controladores PI para as malhas de vazão de combustível e ar e com a ressintonia dos controladores PID de temperatura, que levaram em consideração os modelos médios, obteve-se redução de alguns problemas citados anteriormente.

\subsubsection{Sintonia de Controladores PID}

A sintonia dos controladores PID das malhas de temperatura foi realizada em dois momentos distintos: a primeira foi em 2003, quando, a partir de funções de transferência de segunda ordem com atraso puro de tempo (Tabela 4), foram projetados controladores PID para as malhas de temperatura das zonas de aquecimento e encharque do Forno 4. Utilizou-se o método da síntese direta para ajuste dos valores de $\mathrm{BP}_{N}, \mathrm{~T}_{I} \mathrm{e}$ $\mathrm{T}_{D}$. A segunda foi realizada em 2004, a partir das funções de transferência de primeira ordem com atraso puro de tempo. Nesse caso, foram projetados controladores PID para todas as malhas de temperatura do forno, utilizando-se o método do modelo interno (Seborg et al., 1989). 
Tabela 6: Parâmetros dos controladores PI ajustados para as malhas de vazão (ajuste de 2004).

\begin{tabular}{|c|c|c|c|c|c|c|c|c|c|c|c|c|c|}
\hline & \multicolumn{4}{|c|}{ Modelo } & & \multicolumn{2}{|c|}{ Ajuste Proposto } & \multicolumn{2}{|c|}{ Ajuste Original } & \multicolumn{4}{|c|}{$\frac{\text { original }}{\text { proposto }}$} \\
\hline Malha & $K_{\text {med }}$ & $\tau_{\text {descida }}$ & $\tau_{\text {subida }}$ & $\theta$ & $\tau_{M F}(s)$ & $B P_{N}(\%)$ & $T_{I}(s)$ & $B P_{N}(\%)$ & $T_{I}(s)$ & \multicolumn{2}{|c|}{$\frac{\mathrm{K}_{\mathrm{P}_{\text {original }}}}{\mathrm{K}_{\mathrm{P}_{\text {proposto }}}}$} & \multicolumn{2}{|c|}{$\frac{\mathrm{T}_{\mathrm{I}_{\text {original }}}}{\mathrm{T}_{\mathrm{I}_{\text {proposto }}}}$} \\
\hline & & & & & & & & & & 2004 & 2003 & 2004 & 2003 \\
\hline AFIC411 & 0,63 & 3,5 & 3,0 & 2 & 5,5 & 220,4 & 8 & 260,2 & 25 & 1,2 & 1,6 & 3,1 & 4,2 \\
\hline GFIC411 & 0,54 & 4,69 & 4,69 & 2 & 6,7 & 775 & 5 & 110,0 & 20 & 7,0 & 9,1 & 4 & 5,0 \\
\hline OFIC411 & 59 & 7,13 & 8,0 & 2 & 10 & 174,9 & $\mathbf{8}^{\ddagger}$ & 800,0 & 10 & 0,2 & 0,6 & 1,2 & 1,7 \\
\hline AFIC421 & 0,96 & 26,7 & 22 & 2 & $29 \ddagger$ & 170 & $9 \ddagger$ & 180,0 & 10 & 0,9 & 3,6 & 1,1 & 2,5 \\
\hline GFIC421 & 0,44 & 6,28 & 6,10 & 2 & 8,3 & 443,4 & 7 & 150,0 & 20 & 2,9 & 6,7 & 2,9 & 6,7 \\
\hline OFIC421 & 91 & 9,01 & 7,48 & 1 & 10,0 & 314,8 & 9 & 701,4 & 10 & 0,5 & 0,5 & 1,1 & 1,7 \\
\hline AFIC431 & 0,30 & 5,08 & 4,12 & 2 & 7,1 & 237,7 & 5 & 200,0 & 20 & 1,2 & 1,4 & 4,0 & 4,0 \\
\hline GFIC431 & 0,229 & 5,75 & 5,67 & 2 & 7,8 & 387,9 & 6 & 150,0 & 20 & 2,6 & 6,3 & 3,3 & 6,8 \\
\hline AFIC441 & 0,63 & 7,10 & 7,16 & 2 & 9,1 & 275 & 7,2 & 180,0 & 10 & 1,5 & 2,4 & 1,4 & 2,0 \\
\hline GFIC441 & 0,29 & 4,37 & 4,78 & 2 & 6,8 & 822,5 & 7,2 & 320,0 & 15 & 2,5 & 3,1 & 2,1 & 3,0 \\
\hline AFIC451 & 0,23 & 5,61 & 4,06 & 2 & 7,6 & 397,3 & 5,6 & 220,0 & 20 & 1,8 & 1,7 & 4,0 & 4,0 \\
\hline GFIC451 & 0,11 & 4,37 & 4,78 & 3 & 7,8 & 671,1 & 5 & 160,0 & 15 & 4,2 & 5,3 & 3,0 & 3,0 \\
\hline AFIC461 & 0,322 & 4,75 & 2,5 & 1 & 5,8 & 600,1 & 5 & 200,0 & 10 & 3 & & & \\
\hline GFIC461 & 0,143 & 4,0 & 4,0 & 2 & 6,0 & 583,3 & 4 & 180,0 & 20 & 3 & & & \\
\hline
\end{tabular}

$\ddagger$ A válvula apresentou problemas após a reforma do forno. Após outros testes, obteve-se um tempo de 9 segundos.

Na Tabela 7, são exibidos os ajustes propostos nos dois momentos supracitados para as referidas malhas de temperatura.

Para exemplificar os procedimentos adotados para o projeto dos controladores, são analisadas, nesta seção, as sintonias propostas para a zona de pré-aquecimento. As especificações de projeto tiveram como premissa a intenção de aumentar a velocidade de resposta da malha fechada, porém, projetando um controlador que suporte as variações no processo. Assim, as constantes de tempo de malha fechada $\left(\tau_{M F}\right)$ adotadas para o projeto foram de 400 e de 600 segundos, para o pré-aquecimento superior e inferior, respectivamente. Esses valores foram escolhidos por estarem próximos aos da maior constante de tempo da respectiva malha aberta identificada para o sistema. Essas escolhas conservadoras visam a garantir a não ocorrência de sobressinais, tornando o sistema mais robusto a perturbações e a possíveis mudanças de comportamento do forno devidas a alterações da condição operacional.

Assim sendo, a partir das funções de transferência apresentadas na Seção 1, determinaram-se os parâmetros referentes aos controladores PID utilizando-se o método do modelo interno. Para mostrar os ganhos obtidos, comparam-se os valores originais (ou seja, valores usados antes da primeira sintonia) com os valores propostos em 2003 e 2004 na Tabela 7.

Analisando a Tabela 7, observa-se um aumento significativo nos valores de ganho proporcional $K_{P}$ (ou seja, reduziramse as bandas proporcionais $B P_{N}$ ) chegando quase ao limite do controlador industrial utilizado que é de $7 \%$ para a zona do pré-aquecimento e aquecimento. Apenas na zona de encharque inferior o valor do ganho proporcinal diminuiu em relação ao original.

Com relação ao tempo integral $T_{I}$, observa-se um aumento também significativo tal que os valores propostos são $50 \%$ maiores que os originais para o caso das malhas da zona de pré-aquecimento. $\mathrm{O}$ aumento em $T_{I}$, implica em uma resposta mais lenta de malha fechada, pois o erro transiente é anulado mais lentamente

Nas figuras 16 e 17, são apresentados resultados de simulação que demonstram que, com a redução da banda proporcional (para pouco menos da metade do valor original) e aumento do valor do tempo integral, na zona do préaquecimento inferior, foram observados um aumento na velocidade de resposta (redução de cerca de $10 \%$ na constante de tempo de malha fechada), uma redução do sobressinal e a redução do tempo de acomodação.

Os valores do tempo derivativo $T_{D}$ nos ajustes originais pode ser compreendido quando são analisados em conjunto com os valores de tempo integral. Os valores originais de $T_{D}$ são 3,5 vezes maiores que os propostos. Ou seja, as sintonias originais de $T_{D}$ tentavam corrigir o retardamento provocado 
Tabela 7: Parâmetros dos controladores PID ajustados para as malhas de temperatura ajustados em 2003 e 2004.

\begin{tabular}{|c|c|c|c|c|c|c|c|}
\hline \multicolumn{2}{|c|}{ Malha } & $\begin{array}{l}\text { TIC } \\
411\end{array}$ & $\begin{array}{l}\text { TIC } \\
421\end{array}$ & $\begin{array}{l}\text { TIC } \\
431\end{array}$ & $\begin{array}{l}\text { TIC } \\
441\end{array}$ & $\begin{array}{l}\text { TIC } \\
451\end{array}$ & $\begin{array}{l}\text { TIC } \\
461\end{array}$ \\
\hline \multicolumn{2}{|c|}{$\tau_{M F}(s)$} & 400 & 600 & 120 & 120 & 80 & 100 \\
\hline \multirow{3}{*}{$\begin{array}{c}\text { Ajuste } \\
2004\end{array}$} & BPN (\%) & 13 & 13 & 8,9 & 10,1 & 37,9 & 59,52 \\
\hline & $\mathrm{TI}(\mathrm{s})$ & 365 & 525 & 134 & 149,5 & 116 & 117 \\
\hline & $\mathrm{TD}(\mathrm{s})$ & 14,4 & 14,6 & 21,8 & 22,4 & 21 & 21 \\
\hline \multicolumn{2}{|c|}{$\tau_{M F}(s)$} & - & - & 120 & 120 & 80 & 100 \\
\hline \multirow{3}{*}{$\begin{array}{c}\text { Ajuste } \\
2003\end{array}$} & $\mathrm{BPN}(\%)$ & - & - & 12,4 & 26,6 & 27,2 & 21,2 \\
\hline & $\mathrm{TI}(\mathrm{s})$ & - & - & 150,2 & 146,8 & 70,6 & 121,7 \\
\hline & $\mathrm{TD}(\mathrm{s})$ & - & - & 36,4 & 35,3 & 16,1 & 24,9 \\
\hline \multirow{3}{*}{$\begin{array}{l}\text { Ajuste } \\
\text { original }\end{array}$} & $\mathrm{BPN}(\%)$ & 30 & 30 & 30 & 20 & 38 & 35 \\
\hline & $\mathrm{TI}(\mathrm{s})$ & 180 & 180 & 200 & 300 & 220 & 150 \\
\hline & $\mathrm{TD}(\mathrm{s})$ & 50 & 50 & 50 & 40 & 60 & 60 \\
\hline Original & $\frac{\mathrm{K}_{\mathrm{P}_{\text {original }}}}{\mathrm{K}_{\mathrm{P}_{\text {proposto }}}}$ & - & - & 2,42 & 0,75 & 1,40 & 1,65 \\
\hline versus & $\frac{\mathrm{T}_{\mathrm{I}_{\text {original }}}}{\mathrm{T}_{\mathrm{I}_{\text {proposto }}}}$ & - & - & 1,3 & 2 & 3,1 & 1,2 \\
\hline 2003 & $\begin{array}{l}\mathrm{T}_{\mathrm{D}_{\text {original }}} \\
\mathrm{T}_{\mathrm{D}_{\text {proposto }}}\end{array}$ & - & - & 1,4 & 1,1 & 3,7 & 2,4 \\
\hline Original & $\frac{\mathrm{K}_{\mathrm{P}_{\text {original }}}}{\mathrm{K}_{\mathrm{P}_{\text {proposto }}}}$ & 2,31 & 2,31 & 3,37 & 1,98 & 1,00 & 0,59 \\
\hline versus & $\frac{\mathrm{T}_{\mathrm{I}_{\text {original }}}}{\mathrm{T}_{\mathrm{I}_{\text {proposto }}}}$ & 0,49 & 0,34 & 1,49 & 2,01 & 1,90 & 1,28 \\
\hline 2004 & $\frac{\mathrm{T}_{\mathrm{D}_{\text {original }}}}{\mathrm{T}_{\mathrm{D}_{\text {proposto }}}}$ & 3,47 & 3,42 & 2,29 & 1,79 & 2,86 & 2,86 \\
\hline
\end{tabular}

por $T_{I}$. Além de não conseguir atingir esta meta, quando o tempo derivativo é maior que o indicado, a resposta do sistema torna-se mais oscilatória.

Em relação aos ajustes propostos para as malhas de temperatura da zona do aquecimento e encharque, foi realizada uma mesma análise, mostrando que a resposta do sistema tornouse de duas a quatro vezes mais rápida, comprovando a resposta simulada efetuada com os ajustes originais. Detalhes sobre o projeto e implementação de controladores PID nas outras zonas do forno podem ser encontrados em (Teixeira, 2004; Vidigal, 2004).

\subsubsection{Técnicas Avançadas}

\subsubsection{Controle Chaveado}

Verificou-se que os modelos obtidos para a condição operacional em que a carga do forno é predominantemente de placas quentes têm valores de ganho e constantes de tempo maio-

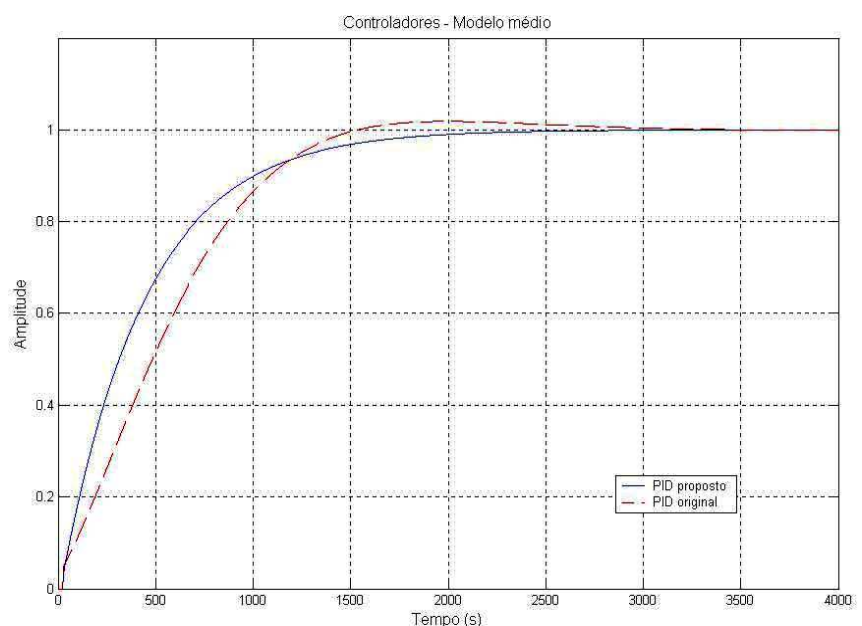

Figura 16: Simulação da resposta ao degrau da malha fechada com o PID proposto e o PID original controlando o modelo médio da zona 411.

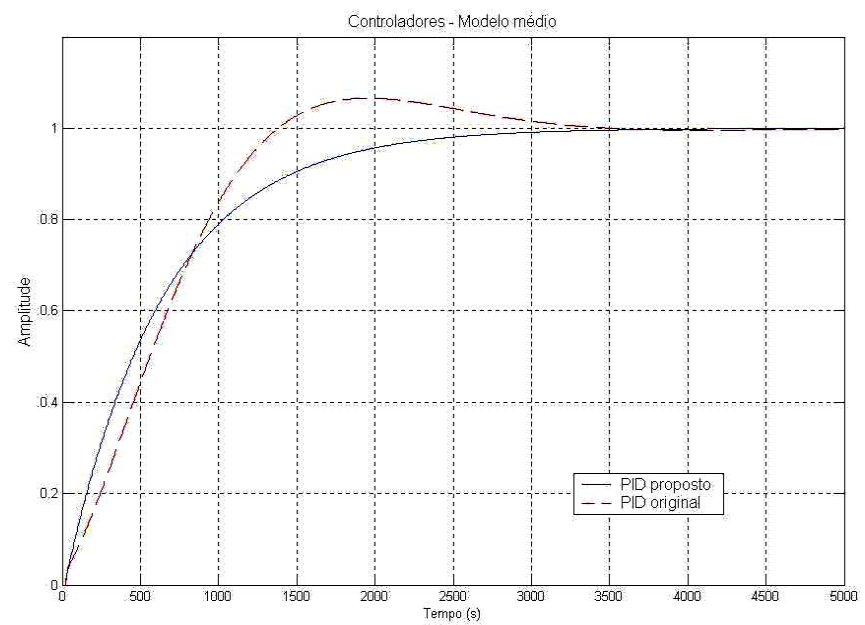

Figura 17: Simulação da resposta ao degrau da malha fechada com o PID proposto e o PID original controlando o modelo médio da zona 421.

res que os obtidos para a condição operacional de carga predominantemente fria. Com base nessas diferenças de comportamento relacionadas à temperatura de enfornamento de placas, é proposta a implementação de uma estratégia de controle chaveado (Jota e Goodwin, 1997) composta de três controladores para a zona do pré-aquecimento. O primeiro deles, chamado controlador hot, para a situação em que a carga é predominantemente quente e, o segundo, chamado controlador cold, para a situação em que a carga é predominantemente fria. Já o terceiro, baseado no modelo médio, deve ser utilizado quando a carga do forno não é caracterizada nem como quente, nem como fria. 
Além dos controladores PID projetados (Tabela 7) para as zonas 411 e 421 com base nos modelos médios, foram simulados, em malha fechada, os controladores projetados para condições de carga quente e fria (Tabela 8). Também foram avaliadas as situações nas quais um controlador hot é usado numa condição fria e vice-versa. As figuras 18 e 19 mostram os resultados obtidos. As respostas possuem as constantes de tempo de malha fechada definidas no projeto, conforme esperado:

- 400 segundos para o controlador hot e 200 segundos para o controlador cold, para a zona 411. Apesar de a constante de tempo de malha fechada utilizada neste projeto ser menor que 265 segundos (conforme Tabela 8), a sintonia do controlador cold ainda é conservadora, pois a constante de tempo do sistema para carga fria é de 250 segundos;

- 600 segundos para o controlador hot e 300 segundos para o controlador cold, para a zona 421. Apesar de a constante de tempo de malha fechada utilizada neste projeto ser menor que 294 segundos (Tabela 8), a sintonia do controlador cold ainda é conservadora, pois a constante de tempo do sistema para carga fria é de 279 segundos.

Tabela 8: Parâmetros dos controladores determinados para a malha TIC-411 e TIC-421 com base nos modelos obtidos para carga Quente e Fria.

\begin{tabular}{|l|l|l|l|l|l|}
\hline \multirow{2}{*}{ Zona/Carga } & \multicolumn{4}{|c|}{$\begin{array}{c}\text { Parâmetros dos } \\
\text { controladores }\end{array}$} \\
\cline { 3 - 6 } \multicolumn{2}{|c|}{} & $\tau_{M F}$ & $\begin{array}{l}\text { BP } \\
(\%)\end{array}$ & $\mathbf{T}_{I}(\mathbf{s})$ & $\begin{array}{l}\mathbf{T}_{D} \\
(\mathbf{s})\end{array}$ \\
\hline \multirow{2}{*}{ TIC 411 } & Quente & 400 & 14,2 & 350 & 14,4 \\
\cline { 2 - 6 } & Frio & 200 & 7,1 & 265 & 14,2 \\
\hline \multirow{2}{*}{ TIC 421 } & Quente & 600 & 10,7 & 806 & 14,7 \\
\cline { 2 - 6 } & Frio & 300 & 6,4 & 294 & 14,2 \\
\hline
\end{tabular}

Para as duas zonas, o uso do controlador hot para carga predominantemente fria torna a resposta do sistema mais lenta, enquanto que o uso do controlador cold para carga quente provoca sobressinais. Conclui-se assim que, nenhum desses dois controladores devem ser adotados nas malhas TIC-411 e TIC-421 para todas as condições operacionais. Resolveu-se adotar o projeto dos controladores PID, para a condição operacional onde a carga não pode ser classificada como quente ou fria.Essa decisão foi fundamentada na seguinte análise: percebeu-se que, apesar da variação dos parâmetros dos modelos, com constantes de tempo variando de 250 a 386 segundos e ganhos de 0,09 a 0,12, para a zona 411 e, com constantes de tempo variando de 279 a 791 segundos e ganhos de 0,06 a 0,14 , para a zona 421 , os controladores projetados

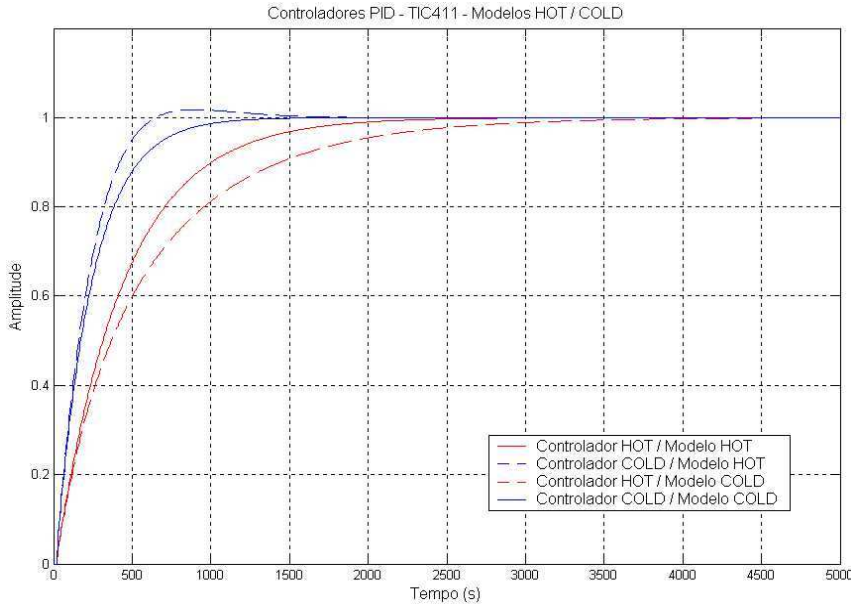

Figura 18: Simulação da resposta ao degrau em malha fechada da zona 411 com os controladores hot e cold, empregando os modelos usados para sintonizá-los. As linhas tracejadas identificam as situações nas quais o controlador cold é testado com carga predominantemente quente e vice-versa. As linhas contínuas referem-se a situações normais.

com base no modelo médio, não resultam em sobressinais significativos em nenhum dos casos simulados. Nas simulações mostradas nas figuras 16 e 17, as constantes de tempo de malha fechada $\left(\tau_{M F}\right)$, projetadas para ser de $400 \mathrm{~s}$ e 600 s, variam de 340 a 517 segundos, e, de 279 e 791 , para as zonas 411 e 421, respectivamente. Isto, reforça ainda mais, os

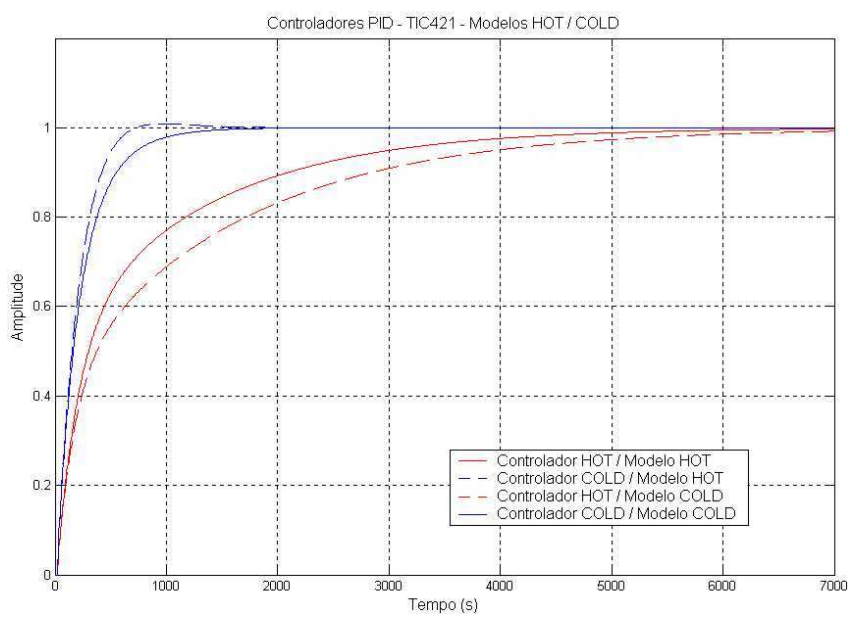

Figura 19: Simulação da resposta ao degrau em malha fechada da zona 421 com os controladores hot e cold, empregando os modelos usados para sintonizá-los. As linhas tracejadas identificam as situações nas quais o controlador cold é testado com carga predominantemente quente e vice-versa. As linhas contínuas referem-se a situações normais. 
aspectos de robustez especificados e considerados no projeto dos controladores médios para a zona do pré-aquecimento.

\subsubsection{Controle Antecipatório}

Para melhorar o desempenho da zona do pré-aquecimento, além da sintonia de um controlador PID ou emprego da técnica de controle chaveado, foi avaliada a possibilidade do uso das técnicas de controle antecipatório, visando reduzir o efeito da principal perturbação dessa zona, conhecida como a entrada de placas, podendo essas serem frias ou quentes.

Seborg e outros (1989) relatam que a qualidade de um controle antecipatório depende de se ter um modelo da planta bem representativo ou uma medida o mais exata possível da perturbação. Para esse forno, baseado nos modelos de $1^{a}$ ordem que relacionam o efeito da entrada de placas no forno, foi projetado o controle antecipatório visando compensar as perturbações da zona do pré-aquecimento, conforme proposto por Seborg e outros (1989) e Jota (1998). As especificações de projeto para sintonia da malha e para o projeto dos controladores cold e hot buscaram obter o projeto de um controlador robusto. Com isso, é esperado que o controlador responda lentamente, para determinadas condições de operação do processo. Espera-se que um controle antecipatório, baseado na entrada de placas na zona do pré-aquecimento, faça com que esta perturbação seja compensada, aumentando a sensibilidade do sistema de controle sem provocar sobressinais.

Foi construído um simulador e foram realizadas diversas simulações visando avaliar a aplicabilidade desta técnica na zona do pré-aquecimento. Para se ter um controle antecipatório mais representativo trabalhou-se no sentido de identificar o efeito da entrada de placa quente no forno. Como o modelo determinado indicou um ganho e uma constante de tempo associada, resolveu-se inicialmente, fazer uma proposição dessa estratégia de controle apenas considerando a relação do ganho obtido do modelo das placas com o ganho da planta nessa zona. Nessas simulações, variações em degrau no setpoint foram aplicadas ao sistema e a simulação de placas frias entrando no forno a cada 400 segundos. Vale destacar que esse tipo de controlador exige uma maior ação de controle, o que pode ser visto no gráfico inferior da Figura 20. Comparou-se o efeito na PV do controle utilizando apenas o controlador PID médio com o PID adicionado do controle antecipatório. No atraso do simulador, foi definido um tempo de 395 segundos, que corresponde ao tempo que a placa começa influenciar a temperatura da zona. Avaliando a resposta do sistema, mostrada na Figura 20, observa-se no gráfico superior, que o controle antecipatório reduz as variações da PV provocadas pela entrada das placas e reduz ligeiramente o tempo de resposta do sistema. A eficácia das implementações do controle chaveado (hot, cold e médio) e
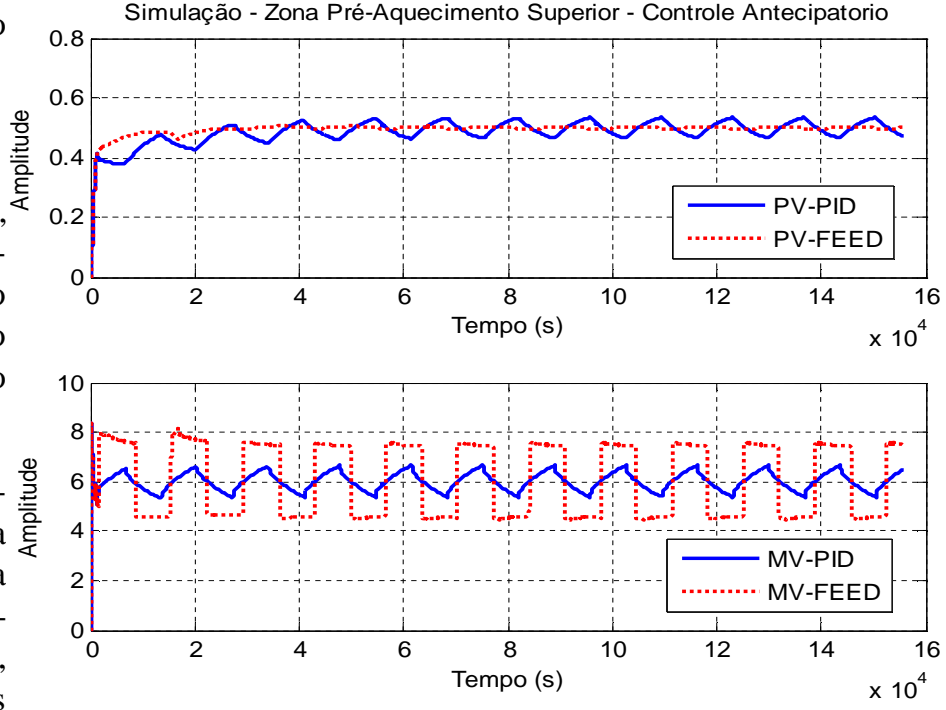

Figura 20: Resposta do simulador do sistema de controle antecipatório em comparação ao PID sintonizado.

do controle antecipatório é sugerida pelos índices GPI relativos aos degraus (antes e depois) e FCC controlando (antes e depois) na Tabela 11 (Seção 5.3).

\subsubsection{Preditor de Smith}

Para melhorar o desempenho do sistema de controle com relação ao atraso puro de tempo, uma das técnicas mais popularmente conhecidas é o chamado "Preditor de Smith" (Shinskey, 1988; Seborg et al.,1989). Essa técnica é baseada no método do modelo interno. Seborg e colaboradores (1989) relatam que o desempenho do Preditor de Smith, para variações de setpoint, pode chegar a ser $30 \%$ melhor do que a de um controlador convencional baseado no critério da integral do erro ao quadrado.

Deve ser dada atenção especial no projeto do preditor, pois em casos em que a dinâmica do processo (especialmente de tempo morto) varia significativamente, o desempenho do controlador pode deteriorar a ponto de tornar o sistema instável. Na essência, o preditor de Smith faz com que o controlador atue com base no erro que seria gerado caso não existisse o tempo morto. Por isso, é necessário ter um modelo representativo do processo e ainda adotar medidas conservadoras no projeto do PI para acomodar possíveis erros de modelagem.

A partir dos modelos equivalentes de $1^{a}$ ordem e dos parâmetros estimados, foram projetados controladores PI e, comparados aos controladores PIDs da zona de encharque. São apresentadas, nesta seção, apenas as simulações que foram feitas visando avaliar a aplicabilidade dessa técnica na zona de encharque. As demais zonas não foram utilizadas a téc- 

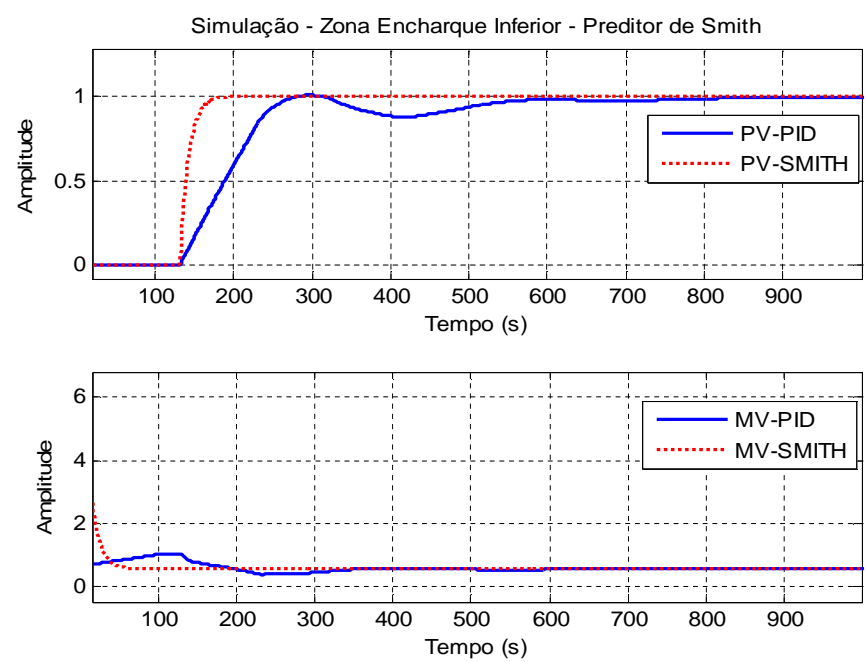

Figura 21: Respostas dos controladores PID em comparação ao preditor de Smith sintonizado para a zona de encharque inferior

nica do preditor de Smith, pois a relação entre o tempo morto e constante de tempo não indicou esta necessidade. Através de um simulador, diversas variações em degrau no setpoint foram aplicadas ao sistema.

Para sintonia dos controladores PI com preditores de Smith, também foi utilizado o método da síntese direta. Através das relações conhecidas, onde considera-se o $\tau_{M F}=0$ para o cálculo do valor preliminar do ganho do controlador, que é a relação utilizada para sistemas de $1^{a}$ ordem sem tempo morto. Já a escolha de $\mathrm{T}_{I}$ foi feita baseando-se na constante de tempo determinada pela técnica dos mínimos quadrados. $\mathrm{Na}$ zona do encharque, para se ter uma melhoria no desempenho, o ganho do controlador atingiu valores até dez vezes maiores que o ganho do controlador PID. Analisando a resposta do sistema, na Figura 21, observa-se que utilizando-se da técnica do preditor Smith, tem-se um aumento significativo na velocidade de resposta (450 segundos) sem ocorrência de sobressinal.

Ao contrário das técnicas de controle chaveado e antecipatório, a implementação do preditor de Smith não foi realizada devido as restrições de hardware do sistema de controle dos fornos.

\subsection{Avaliação de Desempenho}

Até o presente momento, foram empregados critérios tradicionais de avaliação de desempenho de sistemas de controle, como o cálculo do tempo de acomodação e de percentual de sobressinal. Todavia, esses números só podem ser calculados para testes baseados na resposta ao degrau. Final- mente, existe a possibilidade de calcular índices de desempenho convencionais, como o IEA e o IEAT. Porém, a aplicação on-line desses índices seria inviável já que os mesmos cresceriam indefinidamente.

Neste trabalhou, utiliza-se um método numérico, proposto por (Braga e Jota, 1994), que permite a avaliação contínua do desempenho de controladores. A partir desse método, são atribuídas notas de 0 a $100 \%$ em cada período de amostragem para as malhas de controle. Dessa maneira, é possível quantificar o ganho obtido pela sintonia de um controlador como também comparar o desempenho de malhas de controle distintas.

Segundo tal método, a avaliação é desenvolvida com base no cálculo de índices de desempenho conhecidos, como o IEA e IEQ, que medem o erro da variável controlada com relação à referência, IEAT e IEQT, que pesam erros que permanecem ao longo do tempo, IAY e IAU, que quantificam o nível de atividades das variáveis controlada e manipulada, e o IUQ, que caracteriza o esforço de controle. No entanto, estes índices são ponderados e normalizados para que fiquem limitados entre 0 e $100 \%$.

Os índices supracitados são agrupados segundo o ponto de vista de três pessoas: o gerente (MPA), o engenheiro (EPA) e o usuário (UPA). ${ }^{4}$ A Tabela 9 mostra os pesos atribuídos a cada índice a fim de formar essas três notas. Neste trabalho, decidiu-se atribuir a cada grupo um dos três tipos de critérios listados no parágrafo anterior. Assim, o gerente, que é preocupado com o custo financeiro de operação do sistema de controle, avalia o nível de atividade das variáveis controlada e manipulada e o esforço de controle. Notas baixas do gerente podem representar desgaste dos atuadores e falhas operacionais. Ao engenheiro, é incumbida a tarefa de fiscalizar a capacidade de rastreamento da variável controlada, ao passo que o usuário deseja que este rastreamento ocorra com a devida rapidez.

É importante salientar que esse avaliador não mede apenas o desempenho do controlador, mas da malha como um todo, incluindo sensores e atuadores. Assim, uma nota menor pode significar, por exemplo, que o sensor está produzindo sinais ruidosos ou que o atuador está apresentando problemas operacionais (uma válvula agarrando por exemplo).

\section{RESULTADOS EXPERIMENTAIS}

A sintonia nos controladores de temperatura e de vazão e a implementação de novas estratégias de controle proporciona-

\footnotetext{
${ }^{4}$ Nos acrônimos MPA, EPA e UPA, PA refere-se a avaliação de desempenho (performance assessment) e M, E e U a, respectivamente, gerente ( $m a$ nager), engeheiro (engineer) e usuario (user). O termo em inglês Global Performance Index (GPI) pode ser usado em referência à média aritmética dos índices MPA, EPA e UPA.
} 
Tabela 9: Pesos atribuídos aos índices de desempenho no avaliador.

\begin{tabular}{|c|c|c|c|c|c|c|c|}
\hline Índice & IEA & IEQ & IEAT & IEQT & IAY & IAU & IUQ \\
\hline $\begin{array}{c}\text { Gerente } \\
(\text { MPA })\end{array}$ & 0 & 0 & 0 & 0 & 1 & 1 & 1 \\
\hline $\begin{array}{c}\text { Engenheiro } \\
\text { (EPA) }\end{array}$ & 1 & 1 & 0 & 0 & 0 & 0 & 0 \\
\hline $\begin{array}{c}\text { Usuário } \\
(\text { UPA })\end{array}$ & 0 & 0 & 1 & 1 & 0 & 0 & 0 \\
\hline
\end{tabular}

ram aumento da velocidade de resposta das respectivas malhas, minimização das perturbações e diminuição do esforço de controle das válvulas controladoras. Como resultado final, obteve-se uma redução no consumo de combustível.

\subsection{Redução no Consumo de Combustí- vel}

A Tabela 10 aponta que houve uma redução no consumo de combustível em todos os fornos, comparando-se a média de 2004 com a de 2003. A redução percentual de combustível dos Fornos 3, 4 e 5 foi de 4,04\%, 7,02\% e 3,28\%, respectivamente. Como houve redução em todos os fornos, parte do ganho do Forno 4 deve ser atribuído ao aumento da tonelagem efetiva e às melhorias dos procedimentos operacionais. Como os Fornos 4 e 5 são semelhantes, a parcela atribuída à melhoria no Forno $5(3,28 \%)$ foi subtraída do valor de $7,02 \%$ do Forno 4. Sendo assim, a melhoria na redução do consumo devido aos trabalhos realizados no controle dinâmico do Forno 4 foi de 3,74\%. Em 2005, pode-se observar um ligeiro aumento no consumo do forno 4 e um aumento significativo no forno 3 , devido principalmente a parada de manutenção ocorrida em maio e abril, respectivamente. Para o forno 4 , como foram realizadas manutenções nas válvulas de controle, deve-se realizar uma nova ressintonia das malhas de vazão e temperatura e, para o forno 3, como foram substituídas diversas válvulas, mostra a necessidade de realizar uma sintonia similar ao que foi realizado no forno 4 visando melhorar o seu desempenho. Transformando-se essa redução em calorias, considerando uma produção média desse forno de $107 \mathrm{mil} \mathrm{t} / \mathrm{mês}$, a redução de $3,74 \%$ no consumo de combustível equivale a uma economia média mensal em torno de 182 mil litros de óleo (Teixeira et al., 2005).

\subsection{Malhas de Vazão}

Para todos os controladores PI listados na Tabela 6, dezenas de testes em malha fechada foram efetuados para avaliação dos resultados. Alguns refinamentos nos ajustes propostos também foram realizados na planta, visando a obter uma res-
Tabela 10: Dados do consumo de combustíveis dos fornos

\begin{tabular}{|c|c|c|c|}
\hline Forno & $\begin{array}{c}\mathbf{2 0 0 3} \\
(\mathbf{M c a l} / \mathbf{t})\end{array}$ & $\begin{array}{c}\mathbf{2 0 0 4} \\
\text { (Mcal/t) }\end{array}$ & $\begin{array}{c}\mathbf{2 0 0 5} \\
\text { (Mcal/t) }\end{array}$ \\
\hline 3 & 444,4 & 426,3 & 455,1 \\
\hline 4 & 444,4 & 413,2 & 427,4 \\
\hline 5 & 395,9 & 382,9 & 382,4 \\
\hline
\end{tabular}
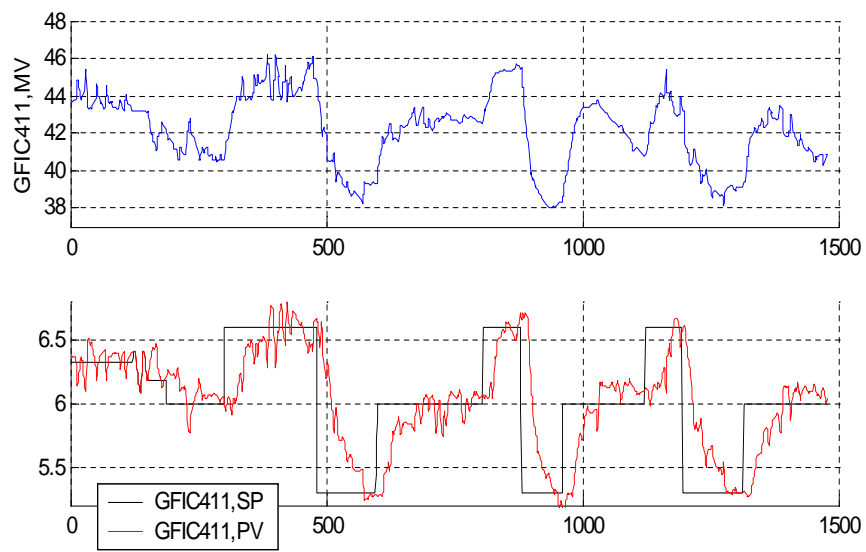

Figura 22: Dados de MV (percentual de abertura da válvula), SP e PV (vazão de gás em $\mathrm{Nm} 3 / \mathrm{h}$ ) da malha de vazão GFIC411 no teste em malha fechada.

posta desejada que atenda as especificações de projeto previamente definidas.

Para exemplificar os resultados gerais obtidos com a sintonia dos controladores de vazão, na Figura 22, são apresentadas as curvas das variáveis manipuladas (MV), controlada (PV) e setpoint dos testes efetuados na malha de vazão do gás de pré-aquecimento superior (GFIC411). Neste teste, foram aplicadas 3 sequiências de variação de SP: de 200 a 500 s (ajuste antigo), de 600 a $850 \mathrm{~s}$ (ajuste proposto) e, de 950 a $1250 \mathrm{~s}$ (ajuste antigo).a

No gráfico superior da Figura 22, comparando-se as seqüências 1 e 3 com a 2, pode-se perceber uma diminuição na variação da MV na seqüência 2, o que proporciona uma redução no esforço de controle. No gráfico inferior, comparando-se as mesmas sequiências, é notável um aumento na velocidade da resposta ao degrau e uma redução no tempo de acomodação.

De uma maneira geral, pode-se dizer que os projetos dos controladores de vazão proporcionaram redução do nível de atividade da variável manipulada e aumento da velocidade de resposta da variável controlada. Tais resultados foram basicamente alcançados com a diminuição dos valores de ganho 


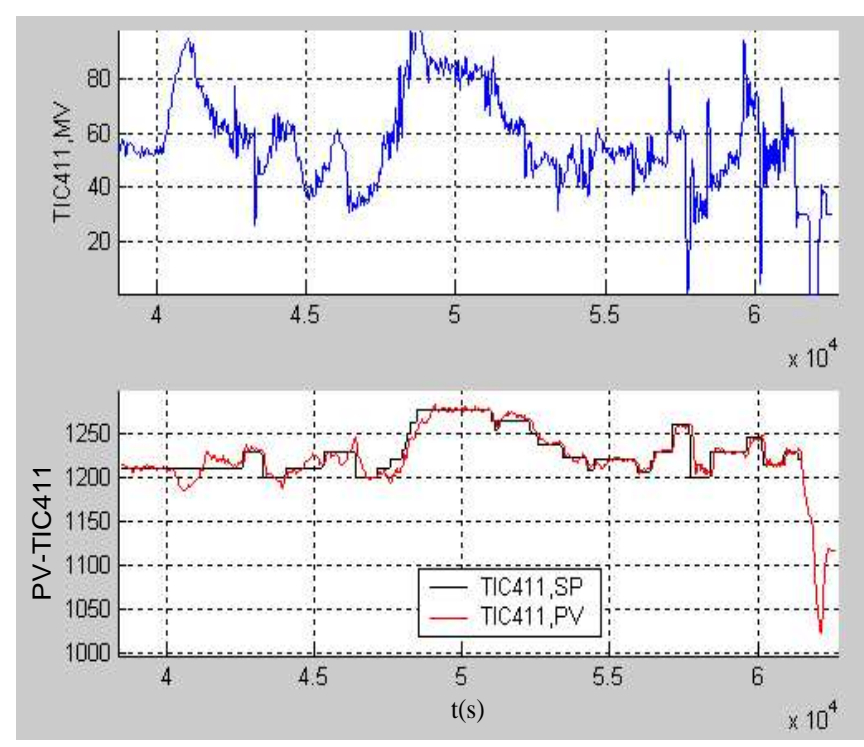

Figura 23: Avaliação de desempenho da malha TIC411 a partir do teste em malha fechada. No gráfico superior, mostra-se o percentual de abertura da válvula e, no inferior, a temperatura da zona em graus (PV) sobreposta ao sinal de setpoint.

proporcional e de tempo integral. Para as malhas de vazão de óleo do pré-aquecimento superior, o ganho proporcional foi maior. Com o tempo integral e ganho proporcional altos, os sistemas de controles ficavam lentos. Assim, com as novas sintonias, evitam-se ocorrências de sobressinal e problemas com os elementos atuadores. Os problemas iniciais observados nas válvulas de controle, como não-linearidades e histerese, foram amenizados satisfatoriamente após a reforma do Forno 4 em junho de 2004. É provável que isto favoreça ainda mais a melhoria no desempenho das malhas de vazão (e, indiretamente, de temperatura) obtido em 2004.

\subsection{Malhas de Temperatura}

A Figura 23 e a Tabela 11 mostram o resultado obtido pela avaliação de desempenho da malha do pré-aquecimento superior (TIC411). Na Seção 4.3, apresenta-se o algoritmo de avaliação de desempenho utilizado.

A Tabela 11 apresenta as notas médias calculadas para cinco condições operacionais distintas: (i) controlador médio proposto (janela 1) e (ii) controlador antigo para condição mista de enfornamento (placas frias e quentes) (janela 2); (iii) semelhante à condição (i) mas com setpoint definido pelo FCC (nível 2) (janela 3); (iv) controlador hot, para predominância de placas no pré-aquecimento enfornadas a temperatura superior a $200^{\circ} \mathrm{C}$ (janela 4 ); (v) e controlador cold, com temperatura de enfornamento inferior a $200^{\circ} \mathrm{C}$ (janela 5). Apenas na janela 3, o sinal de setpoint foi gerado pelo sistema de
Tabela 11: Avaliação de desempenho da malha TIC411.

\begin{tabular}{|l|c|c|c|c|}
\hline \multicolumn{1}{|c|}{ Janela de Tempo } & MPA & EPA & UPA & $\begin{array}{c}\text { GPI } \\
\text { (índice } \\
\text { médio) }\end{array}$ \\
\hline $\begin{array}{l}\text { 1) 42500 a 44500s } \\
\text { Degrau - Cont. Médio } \\
\text { Proposto Condição Mista }\end{array}$ & 92,7 & 76,9 & 55 & 74,9 \\
\hline $\begin{array}{l}\text { 2) 45000 a 47500s. } \\
\text { Degrau - Cont. Antigo } \\
\text { Condição Mista }\end{array}$ & $\mathbf{9 2 , 2}$ & $\mathbf{6 1 , 1}$ & $\mathbf{2 8 , 7}$ & $\mathbf{6 0 , 7}$ \\
\hline $\begin{array}{l}\text { 3) 47600 a 56000s } \\
\text { FCC - Cont. Médio Pro- } \\
\text { posto Condição Mista }\end{array}$ & 86,6 & 74,1 & 55,9 & 72,2 \\
\hline $\begin{array}{l}\text { 4) 57000 a 59000s } \\
\text { Degrau - Cont. Proposto } \\
\text { Hot (temp. placas }> \\
\text { 200 }{ }^{\circ} \text { C) }\end{array}$ & $\mathbf{8 7}$ & $\mathbf{6 4 , 6}$ & $\mathbf{3 1 , 3}$ & $\mathbf{6 1}$ \\
\hline $\begin{array}{l}\text { 5) 59000 até 61200s } \\
\text { Degrau - Cont. Proposto } \\
\text { Cold (temp. placas } \\
\text { 200 }{ }^{\circ} \text { C) }\end{array}$ & 88,7 & 87,5 & 74 & 83,4 \\
\hline
\end{tabular}

nível 2 (FCC). Para as demais janelas, o setpoint foi gerado manualmente durante a execução dos testes.

Comparando-se o índice de desempenho global (GPI) nas janelas 1 e 2, percebe-se uma melhora de $14,2 \%$; nas janelas 4 e 2 , uma melhora de $0,3 \%$; e, nas janelas 5 e 2, uma melhora de $22,7 \%$ no desempenho da malha. A janela 3 acompanha a tendência da janela 1 . Pode-se perceber que, quando o controlador médio é testado, os índices apresentam valores superiores ao controlador antigo.

Pode-se observar, pelos índices obtidos no avaliador de desempenho, que os desvios entre a variável controlada e o setpoint diminuíram notavelmente. Outros ganhos, além da redução do combustível, podem ser citados porque a variável controlada acompanha melhor o setpoint. Acredita-se que melhoria da qualidade da placa aquecida, redução do índice de carepa ${ }^{5}$ do forno e redução do nível de manutenção das válvulas controladas sejam verificáveis.

Em termos gerais, foi possível aumentar de duas a três vezes a velocidade de resposta das malhas de temperatura das zonas de pré-aquecimento, aquecimento e de encharque em relação aos controladores originais, aumentando-se o ganho proporcional e reduzindo-se os valores de tempo derivativo. Somente para a malha de temperatura da zona de encharque superior e inferior, o ganho proporcional foi reduzido. Em relação ao tempo integral, pode-se afirmar que as melhorias

\footnotetext{
${ }^{5}$ Percentual de defeito do produto devido à camada de óxidos que se forma sobre a superfície do aço quando em altas temperaturas.
} 
foram devidas ao aumento deste parâmetro na zona de préaquecimento e diminuição na zona de aquecimento e encharque. Os resultados obtidos a partir do avaliador de desempenho para as malhas de temperatura mostram-se coerentes com os dados dos testes realizados. Uma discussão detalhada das sintonias pode ser encontrada (Teixeira, 2004; Teixeira, 2005).

Finalmente, pode-se destacar que as ações de melhoria da sintonia das malhas e das novas estratégias de controle implementadas são coerentes com os resultados obtidos quanto à economia de combustível no forno.

\section{CONCLUSÕES}

Este trabalho apresenta os resultados obtidos relativos às melhorias de desempenho atingidas no controle dinâmico de um forno de reaquecimento de placas da linha de tiras a quente da Usiminas. Essas melhorias proporcionaram uma redução mensal aproximada de 3,7\% no consumo do combustível.

Para tal, num primeiro momento, utilizou-se, uma metodologia simples para o projeto de controladores PI e PID para malhas de controle de vazão e de temperatura de um forno de reaquecimento, respectivamente. Tal metodologia foi baseada: (i) na realização de testes ao degrau nas malhas estudadas; (ii) obtenção de modelos que caracterizassem a dinâmica dominante das mesmas (cuja estimação de parâmetros se deu com o uso dos métodos da resposta complementar e dos mínimos quadrados); (iii) validação dos modelos; (iv) projeto (a partir dos métodos da síntese direta e do modelo interno), simulação e implementação dos controladores PI e PID; e (v) avaliação de desempenho das malhas. A referida metodologia também pode ser aplicada a processos cuja resposta possa ser aproximada por funções de transferência de primeira ou de segunda ordem com atraso puro de tempo.

Na etapa seguinte, almejando melhorar o comportamento dinâmico das malhas de controle de temperatura da zona de pré-aquecimento (onde as placas recebem maior parte da energia necessária para seu aquecimento), optou-se por tratar efeitos de perturbação, tais como a variação da temperatura média das placas enfornadas e acoplamento com zonas vizinhas. Quanto ao acoplamento, obteve-se e analisou-se a matriz de ganhos relativos do forno de estudo. Tal análise indicou entre quais zonas o acoplamento dinâmico é mais pronunciado. Dessa maneria, após obtenção de modelos que caracterizam tais perturbações, estratégias de controle avançado (controle chaveado e controle antecipatório) foram implementadas para amenizar os problemas supracitados. No caso da zona de encharque, investigaram-se os ganhos em implementar preditor de Smith, já que as malhas de temperatura correspondentes apresentavam atraso puro de tempo significativo quando comparado ao valor da constante de tempo dominante.

De uma forma geral, os controladores sintonizados para as malhas de vazão acarretaram na redução do nível de atividade da variável manipulada e no aumento da velocidade de resposta da variável controlada. Semelhantemente, aumentou-se de duas a quatro vezes a velocidade de resposta das malhas de temperatura. Essas melhorias de desempenho acarretaram na redução de combustível mencionada.

\section{AGRADECIMENTOS}

Os autores agradecem à Usiminas pelo suporte técnico e financeiro e aos colegas da Usiminas e UFMG (em especial ao Eng. Caio Henrique Vidigal) pela contribuição nas discussões e implementações das propostas.

\section{REFERÊNCIAS}

AGUIRRE, L. A. (2004): Introdução à Identificação de Sistema: Técnicas Lineares e Não-Lineares Aplicadas a Sistemas Reais. $2^{a}$ Edição. Editora UFMG.

ÅSTRÖM, K. e HÄGGLUND, T. (1995): PID Controllers: Theory Design and Tunning. 2nd Edition. Ed. ISA.

ÅSTRÖM, K. e HÄGGLUND, T. (2001): The Future of PID Control. Control Eng. Practice, 9, pp.1163-1175.

BRAGA, A. R. e JOTA, F. G. (1994): Critérios Múltiplos para Avaliação On-Line de Desempenho de Controladores Industriais. In: $10^{\circ}$ Congresso Brasileiro de Automática e $6^{\circ}$ Congresso Latino-Americano de Controle Automático, 19 a 23 de setembro de 1994, Rio de Janeiro, Anais, Sociedade Brasileira de Automática, v.1, pp.112-114.

BRISTOL, E.H. (1966) On a New Measure of Interactions for Multivariable Process Control, IEEE Trans. Auto. Control, AC-11, pág. 133.

CLARKE, D.W., MOHTADI, C. TUFFS, D., Generalized Predictive Control, OUEL Report, University of Oxford, United Kingdom, 1986.

DESBOROUGH, L.; NORDH, P.N e MILLER, R. (2001): Control System Reliability - Process Out of Control. In Tech with Industrial Computing, August, pp.52-55.

DOEBELIN, E.O. (1980): System Modeling and Response. Ed. John Wiley \& Sons Inc, New York.

DOEBELIN, E.O. (1990): Measurement Systems: Application and Design, 2nd Edition, Ed. McGraw-Hill International. 
DORF, R. C. e BISHOP, R. H. (1998): Sistemas de Controle Moderno. $8^{a}$ Edição. Ed. LTC.

DUNOYER, A.; BURNHAM, K.J. e MCALPINE, T.S. (1997): Self-tuning control of an industrial pilot-scale reheating furnace: Design principles and application of a bilinear approach. Control Theory and Applications, IEE Proceedings, v.144, i.1, January. pp. 25 -31.

GARCÍA, D.F.; SIERRA, M.; RODRÍGUEZ, R.; CAMPOS, A. e DÍAZ, R. (1998): Development of Scalable RealTime Observers for Continuous Reheating Furnaces Based on Mathematical Modeling Techniques. Conference Record - IAS Annual Meeting (IEEE Industry Applications Society), v. 3. pp. 2207-2216.

JOTA, F. G. ; GOODWIN, G. C. (1997): Switching control: some stability results. Proceedings of the 36th Conference on IEEE Decision and Control, v. 3. pp. 22092211.

JOTA, F. G. (1998): Técnicas de Controle de Processos Industriais. Notas de aula. Universidade Federal de Minas Gerais, Belo Horizonte.

JIONG, J. (1989): An Application of AI Control Strategy to a Walking Beam Reheating Furnace. Computers in Industry, 13, pp.253-259.

KO, H.S.; KIM, J.; YOON, T.; LIM, M.; YANG, D.R. e JUN, I.S. (2000): Modeling and Predictive Control of a Reheating Furnace. Proceedings of the American Control Conference, Chicago, Illinois, p.2725-2729.

KUSTERS, A. e VAN DITZHUIJZEN, G.A.J.M. (1994): MIMO System Identification of a Slab Reheating Furnace. 3rd IEEE Conference on Control Applications, Glasgow, 24-26 August. pp. 1557-1563.

LJUNG, L. (1987): System Identification, Theory for the User. New Jersey. Prentice Hall.

PEDERSEN, L.M. e WITTENMARK, B. (1998): On the Reheat Furnace Control Problem. Proceedings of 17th American Control Conference, Philadelphia, Pennsylvania. pp. 3811-3815.

PEDERSEN, L.M. e WITTENMARK, B. (2001): A Simple Slab Temperature Model. Steel Technology International. pp.74-78.

PHILLIPS, C. L. e NÄGLE, H. T. (1995): Digital Control System Analysis and Design, $3^{\text {rd }}$ Edition, PrencticeHall.

RODRIGUES, D. D. ; BHERING, H. S. ; OLIVEIRA, J. C. R. ; JOTA, F. G. (1998): Uma Metodologia Prática e Simples para Análise e Projeto de Controladores PID. II
Congresso Mineiro de Automação / V Simpósio Regional de Instrumentação (ISA/GRINST), Belo Horizonte, MG. pp. 251-259.

ROHÁL'-ILKIV, B.; ZELINKA, P. e RICHTER R. (1994): Multivariable Adaptive Temperature Control for a Reheating Furnace. IEE Colloquium, n.18, January, Published by IEE, Michael Faraday House, England.

SEBORG, D. E., EDGAR, T. F. e MELLICHAMP, D. A. (1989): Process Dynamics and Control. John Wiley \& Sons.

SHINSKEY, F. G. (1988): Process Control Systems: Application, Design and Tuning. McGraw-Hill, 3 ed.

SUGITA, Y., KAYAMA, M. e MOROOKA, Y. (1997): Improving Tuning Capability of the Adjusting Neural Network. Proceedings of IEEE International Conference on Neural Networks, v.2, pp. 761-766.

TEIXEIRA, B. O. S. (2004): Modelagem e Sintonia de Controladores para um Forno de Reaquecimento. Monografia de Graduação em Engenharia de Controle e Automação. Universidade Federal Minas Gerais.

TEIXEIRA, M. H. (2005): Modelagem e Controle do Forno de Reaquecimento de placas da Linha de Tiras a Quente da Usiminas. Dissertação de Mestrado em Engenharia Elétrica. Universidade Federal de Minas Gerais.

TEIXEIRA, M. H.; TEIXEIRA, B. O. S.; FREITAS, L. C. D.; DO CARMO, R. A. e JOTA, F. G. (2005): Eficientização Energética em Fornos de Reaquecimento de Placas via Sintonia de Controladores de Vazão e de Temperatura. Congresso Brasileiro de Eficiência Energética (CBEE), Belo Horizonte - MG, Brasil. Anais, pp. 274279

VAN DEN HOF, P.M.J. (1998). Closed-Loop Issues in System Identification. Annual Reviews in Control, V. 22, pp. 173-186. Elsevier Science, Oxford, UK

VAN DITZHUIJZEN, G.A.J.M.; STAALMAN, D. e KOORN, A. (2002): Identification and Model Predictive Control of a Slab Reheating Furnace. Proceedings of the 2002 IEEE International Conference on Control Applications, Glasgow, Scotland, September 18-20. pp. 361-366.

VIDIGAL, C. H. (2004): Modelagem e Controle das Malhas de Temperatura do Pré-aquecimento de um Forno de Reaquecimento de Placas da USIMINAS. Monografia de Graduação em Engenharia de Controle e Automação. Universidade Federal de Minas Gerais. 
WANG, Z.; CHAI, T.; GUAN, S. e SHAO, C. (1999a): Hybrid Optimization Setpoint Strategy for Slab Reheating Furnace Temperature. Proceedings of the American Control Conference, San Diego, California, USA, June. pp. 4082-4086.

WANG, Z.; SHAO, C. e CHAI, T. (1999b): Application of Multivariable Technique in Temperature Control of Reheating Furnaces. Proceedings of the 1999 IEEE International Conference on Control Applications, Kohala Coast, Hawaii, USA, August 22-27. pp. 29-32.

WICK, H. J. e KÖSTER, F. (1999) Estimation of Temperature Profiles of Slabs in a Reheat Furnace by using the Kalman Filter. Proceedings of the IEEE. International Symposium on Computer Aided Control Systems Design, Hawai, USA, August 22-27, pp.613-617.

YANG, Y. e LU, Y. (1986): Development of a Computer Control Model for Slab Reheating Furnaces. Сотрuters in Industry, 7, 2, pp.145-154.

YANG, Y. e LU, Y. (1988): Dynamic Model Based Optimization Control for Reheating Furnaces. Computers in Industry, 10, pp.11-20.

YOSHITANI, N., UEYAMA, T. e USUI, M. (1994): Optimal Slab Heating Control with Temperature Trajectory Optimization. IECON Proceedings (Industrial Electronics Conference), v. 3, pp.1567-1572.

ZHANG, B.; CHENG, Z.; XU, L.; WANG, J.; ZHANG, J.; SHAO, H. (2002): The Modeling and Control of a Reheating Furnace. Proceedings of the American Control Conference, May, 8-10. pp. 3823-3828. 